Article

\title{
Rechargeable Energy Storage Systems for Plug-in Hybrid Electric Vehicles-Assessment of Electrical Characteristics
}

\section{Noshin Omar ${ }^{1,2, *}$, Mohamed Daowd ${ }^{1}$, Peter van den Bossche ${ }^{2}$, Omar Hegazy ${ }^{1}$, Jelle Smekens ${ }^{1}$, Thierry Coosemans ${ }^{1}$ and Joeri van Mierlo ${ }^{1}$}

1 Vrije Universiteit Brussel, Pleinlaan 2, Brussel, 1050, Belgium; E-Mails: mdaowd@vub.ac.be (M.D.); omar.hegazy@vub.ac.be (O.H.); jsmekens@vub.ac.be (J.S.); thierry.coosemans@vub.ac.be (T.C.); jvmierlo@vub.ac.be (J.M.)

2 Erasmus University College, Nijverheidskaai 170, Brussel, 1070, Belgium; E-Mail: peter.van.den.bossche@ehb.be

* Author to whom correspondence should be addressed; E-Mail: noshomar@vub.ac.be; Tel./Fax: +32-255-915-12.

Received: 10 April 2012; in revised form: 30 July 2012 / Accepted: 31 July 2012 /

Published: 10 August 2012

\begin{abstract}
In this paper, the performances of various lithium-ion chemistries for use in plug-in hybrid electric vehicles have been investigated and compared to several other rechargeable energy storage systems technologies such as lead-acid, nickel-metal hydride and electrical-double layer capacitors. The analysis has shown the beneficial properties of lithium-ion in the terms of energy density, power density and rate capabilities. Particularly, the nickel manganese cobalt oxide cathode stands out with the high energy density up to $160 \mathrm{Wh} / \mathrm{kg}$, compared to $70-110,90$ and $71 \mathrm{Wh} / \mathrm{kg}$ for lithium iron phosphate cathode, lithium nickel cobalt aluminum cathode and, lithium titanate oxide anode battery cells, respectively. These values are considerably higher than the lead-acid (23-28 Wh/kg) and nickel-metal hydride $(44-53 \mathrm{Wh} / \mathrm{kg})$ battery technologies. The dynamic discharge performance test shows that the energy efficiency of the lithium-ion batteries is significantly higher than the lead-acid and nickel-metal hydride technologies. The efficiency varies between $86 \%$ and $98 \%$, with the best values obtained by pouch battery cells, ahead of cylindrical and prismatic battery design concepts. Also the power capacity of lithium-ion technology is superior compared to other technologies. The power density is in the range of 300-2400 W/kg against 200-400 and 90-120 W/kg for lead-acid and nickel-metal hydride, respectively. However, considering the influence of energy efficiency, the power density is in the range of 100-1150 W/kg. Lithium-ion batteries optimized for high energy are at the
\end{abstract}


lower end of this range and are challenged to meet the United States Advanced Battery Consortium, SuperLIB and Massachusetts Institute of Technology goals. Their association with electric-double layer capacitors, which have low energy density (4-6 Wh/kg) but outstanding power capabilities, could be very interesting. The study of the rate capability of the lithium-ion batteries has allowed for a new state of charge estimation, encompassing all essential performance parameters. The rate capabilities tests are reflected by Peukert constants, which are significantly lower for lithium-ion batteries than for nickel-metal hydride and lead-acid. Furthermore, rate capabilities during charging have been investigated. Lithium-ion batteries are able to store about $80 \%$ of the capacity at current rate $2 \mathrm{I}_{\mathrm{t}}$, with high power cells accepting over $90 \%$. At higher charging rates of $5 \mathrm{I}_{\mathrm{t}}$ or more, the internal resistance impedes charge acceptance by high energy cells. The lithium titanate anode, due to its high surface area $\left(100 \mathrm{~m}^{2} / \mathrm{g}\right.$ compared to $3 \mathrm{~m}^{2} / \mathrm{g}$ for the graphite based anode) performs much better in this respect. The behavior of lithium-ion batteries has been investigated at different conditions. The analysis has leaded us to a new lithium ion battery model. This model will be compared to existing battery models in future research contributions.

Keywords: lithium-ion batteries; energy density; rate capabilities; power density; performance tests; HPPC-test; battery model

\section{Introduction}

As the global economy begins to strain under the pressure of rising petroleum prices and environmental concerns, research have spurred into the development of various types of clean energy transportation systems such as Hybrid Electric Vehicles (HEVs), Battery Electric Vehicles (BEVs) and Plug-In Hybrid Electric Vehicles (PHEVs) [1-5]. Especially PHEVs acquire the most attention due to the combination of electrical source and conventional engine. This type of vehicle provides the user a considerable pure electrical range and also an extended range, which can be performed by a conventional Internal Combustion Engine (ICE). The establishment of a Rechargeable Energy Storage System (RESS) that can support the output power during acceleration, efficiently use the regenerative energy and perform for a considerable cycle life are the critical aspects to be met by battery technologies [6-8].

During the last decade, a series of hybridization topologies have been proposed in order to enhance the power density and cycle life performances of energy storage systems [9-12]. In [13-19] is documented that the combination of Valve-Regulated Lead-Acid (VRLA) battery and Electrical Double-Layer Capacitors (EDLCs) can result into an extension of the battery life and an increase of the energy efficiency and power capabilities. However, in [13] Omar et al. underlined that the association with EDLCs is still expensive due to the high cost price of the DC-DC converter.

In [8] Cooper et al. proposed a new technology, called UltraBattery. This RESS technology combines in the same battery cell the advantages of the EDLC and lead-acid batteries by using an 
asymmetric approach. However, this technology is still in developing process and its real performances are under investigation.

From the beginning of the nineties, lithium-ion technology has received considerable attention due to the high energy density, power capabilities compared to VRLA, nickel-metal hydride and nickel cadmium based technologies [20-34]. Due to the lowest standard reduction potential $\left(\mathrm{E}^{\circ}=-3.04 \mathrm{~V}\right)$, equivalent weight $(\mathrm{M}=6.94 \mathrm{~g} / \mathrm{mol})$ and high exchange current density, lithium as an electrode can be considered as a most favourable material [35] as it is presented in Table 1.

Table 1. Standard potential [35].

\begin{tabular}{cc}
\hline Cathode (reduction), half reaction & Standard potential $\mathbf{E}^{\circ}[\mathbf{V}]$ \\
\hline $\mathrm{Li}^{+}(\mathrm{aq})+\mathrm{e}^{-} \rightarrow \mathrm{Li}(\mathrm{s})$ & -3.04 \\
$\mathrm{~K}^{+}(\mathrm{aq})+\mathrm{e}^{-} \rightarrow \mathrm{K}(\mathrm{s})$ & -2.92 \\
$\mathrm{Ca}^{2+}(\mathrm{aq})+2 \mathrm{e}^{-} \rightarrow \mathrm{Ca}(\mathrm{s})$ & -2.76 \\
$\mathrm{Na}^{+}(\mathrm{aq})+\mathrm{e}^{-} \rightarrow \mathrm{Na}(\mathrm{s})$ & -2.71 \\
$\mathrm{Zn}^{2+}(\mathrm{aq})+2 \mathrm{e}^{-} \rightarrow \mathrm{Zn}(\mathrm{s})$ & -0.76 \\
$2 \mathrm{H}^{+}+2 \mathrm{e}^{-} \rightarrow \mathrm{H}_{2}$ & 0 \\
$\mathrm{Cu}^{2+}(\mathrm{aq})+2 \mathrm{e}^{-} \rightarrow \mathrm{Cu}(\mathrm{s})$ & 0.34 \\
$\mathrm{~F}_{2}(\mathrm{~g})+2 \mathrm{e}^{-} \rightarrow 2 \mathrm{~F}^{-}(\mathrm{aq})$ & 2.87 \\
\hline
\end{tabular}

Contrary to the traditional redox reactions based batteries, rechargeable lithium-ion batteries works according so called "intercalation" or "insertion" process. During discharge, lithium-ions are extracted from the anode electrode and migrate across the electrolyte into the crystal lattice of the cathode material, without changing of the crystal structure (see Figure 1). The reverse mechanism occurs during charging [35].

Figure 1. Charge and discharge process of secondary lithium-ion batteries [35].
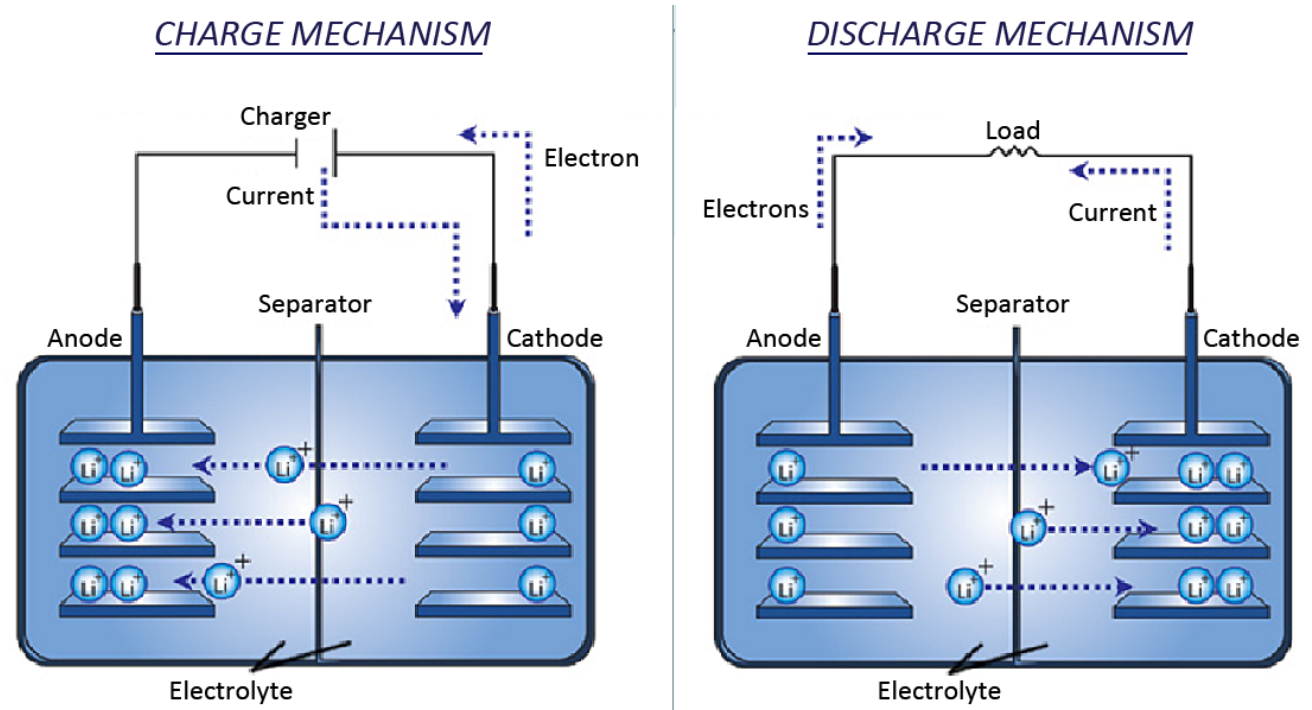

The lithium-ion family encompasses a number of chemistries based of the used materials in the anode and cathode (see Table 2). According to the references [36-39], the potential lithium-ion chemistries candidates in PHEVs are: 
- Lithium iron phosphate $\left(\mathrm{LiFePO}_{4}\right)$;

- Lithium nickel manganese cobalt oxide $\left(\left(\mathrm{LiNiMnCoO}_{2}\right)\right.$;

- Lithium nickel cobalt aluminum $\left(\mathrm{LiNiCoAlO}_{2}\right)$;

- Lithium titanate oxide $\left(\mathrm{LiTiO}_{2}\right)$;

- Lithium manganese spinel oxide $\left(\mathrm{LiMn}_{2} \mathrm{O}_{4}\right)$.

Table 2. Comparison of the most relevant anode and cathode materials [38,39].

\begin{tabular}{ccc}
\hline Positive/negative electrode material & $\begin{array}{c}\text { Nominal cell voltage } \\
\text { [V] }\end{array}$ & $\begin{array}{c}\text { Specific capacity } \\
\text { Positive/negative } \\
\text { [mAh/g] }\end{array}$ \\
\hline $\mathrm{LiCoO}_{2} /$ graphite & 3.7 & $120 / 370$ \\
$\mathrm{LiMn}_{2} \mathrm{O}_{4}\left(\mathrm{LMO}^{\prime} /\right.$ graphite & 3.7 & $100 / 370$ \\
$\mathrm{LiNiO}_{2} /$ graphite & 3.7 & $170 / 370$ \\
$\mathrm{LiFePO}_{4}(\mathrm{LFP}) /$ graphite & 3.3 & $150-160 / 370$ \\
$\mathrm{LiCoNiMnO}\left(\mathrm{NMC}_{2} /\right.$ graphite & 3.7 & $130-160 / 370$ \\
$\mathrm{LiNiMnCoO}_{2}$ graphite & 3.7 & $200 / 370$ \\
$\mathrm{LiNiCoAlO}_{2}\left(\mathrm{NCA}^{\prime} /\right.$ graphite & 3.7 & $180 / 370$ \\
$\mathrm{Graphite} / \mathrm{LiTiO}_{2}(\mathrm{LTO})$ & 2.2 & $175 / 160$ \\
\hline
\end{tabular}

In portable applications, lithium cobalt oxide $\left(\mathrm{LiCoO}_{2}\right)$ based batteries have a superior position. However, the applicability of this battery chemistry is not appropriate in the PHEVs due to their less beneficial thermal stability, high cost and limited availability of cobalt [39-45].

In $[44,45]$ it is documented that battery cell capacity decreases very fast during cycling. Amatucci et al. reported that less lithium could be intercalated during discharge due to the fact that cobalt is dissolved in the electrolyte when the electrode is delithiated during charging. The second reason is due to the formation of the $\mathrm{CoO}_{2}$ layer formed after delithiated, which also results in minimization of the cathode surface, as consequence increase of the impedance and less capacity for lithium interaction $[40,46,47]$. In order to overcome this problem, $\mathrm{LiCoO}_{2}$ is replaced by a mixture of cobalt and nickel. The most used composition is $\mathrm{LiCo}_{0.2} \mathrm{Ni}_{0.8} \mathrm{O}_{2}$ [48]. Here, nickel is significantly cheaper than cobalt and the battery cost can be reduced [49]. However, this composition is less ordered compared to $\mathrm{LiCoO}_{2}[49,50]$. In order to improve the stability of $\mathrm{LiCoO}_{2}$ or $\mathrm{LiNiO}_{2}$ or $\mathrm{LiCo}_{0.2} \mathrm{Ni}_{0.8} \mathrm{O}_{2}$, aluminium can be added. This composition is $\mathrm{LiNi}_{0.8} \mathrm{Co}_{0.15} \mathrm{Al}_{0.05} \mathrm{O}_{2}$. Aluminium doping is beneficial to suppress the impedance increase by stabilization the charge transfer impedance on the cathode side and improvement of the electrolyte stability [39].

Lithium iron phosphate $\left(\mathrm{LiFePO}_{4}\right)$ with olivine structure has been proposed as a promising candidate to overcome the weakness of the earlier cathode materials [50] (see Figure 2). The $\mathrm{LiFePO}_{4}$ based batteries have high thermal stability and are much less expensive than the earlier mentioned battery chemistries. Moreover they are non-toxic [50]. In contradiction to $\mathrm{LiCoO}_{2}, \mathrm{LiCo}_{0.2} \mathrm{Ni}_{0.8} \mathrm{O}_{2}$, $\mathrm{LiNi}_{0.8} \mathrm{Co}_{0.15} \mathrm{Al}_{0.05} \mathrm{O}_{2}$ and $\mathrm{LiNi}_{1 / 3} \mathrm{Mn}_{1 / 3} \mathrm{Co}_{1 / 3} \mathrm{O}_{2}, \mathrm{LiFePO}_{4}$ batteries do not release oxygen at elevated temperatures, which can react with the electrolyte and results in thermal runaway $[51,52]$. 
Figure 2. Olivine structure [51].

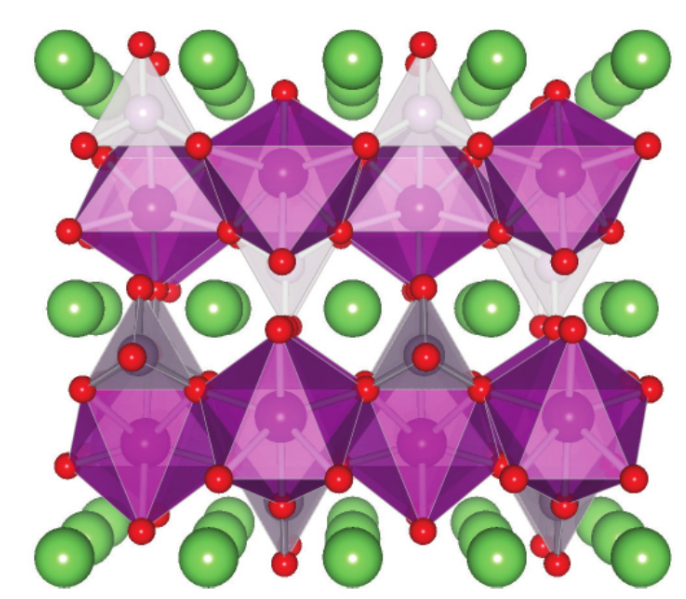

From the point of view of the anode material, graphite seems the most appropriate candidate due to the high specific capacity: $370 \mathrm{mAh} / \mathrm{g}$ [52,53]. However, graphite based anodes have some particular problems such as less beneficial performances at low temperatures and formation of the passivating Solid Electrolyte Interface (SEI) layer as presented in Figure 3. In the last years new anodic materials have been proposed based on Titanate oxides $\left(\mathrm{TiO}_{2}\right)$ [54,55]. According to Brousseley et al. and Colbow et al., lithium titanate oxide is a more ideal insertion material with a specific capacity of $175 \mathrm{mAh} / \mathrm{g}[54,55]$. It is safer and no SEI layer occurs on the anode surface.

Figure 3. Formation of SEI layer [50].

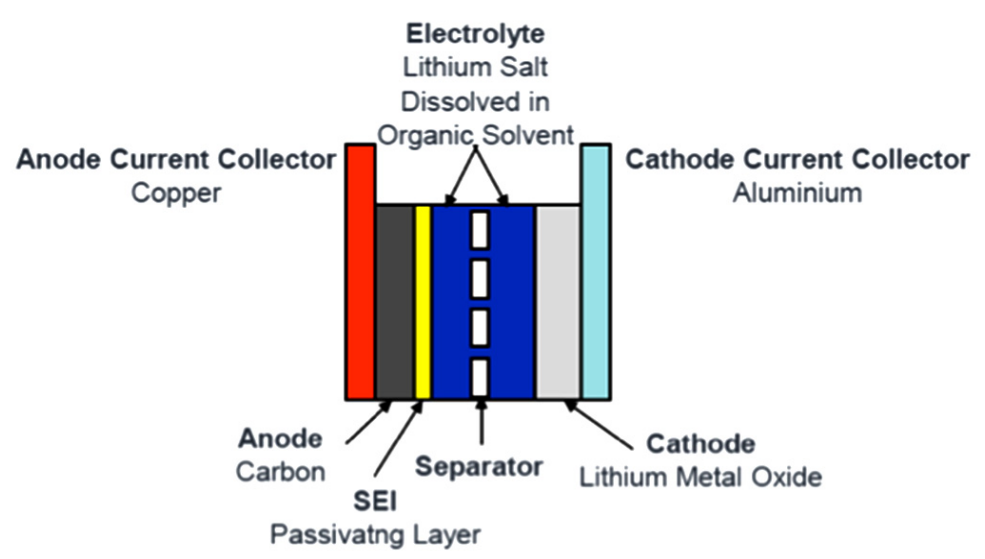

Regarding liquid electrolytes in lithium-ion based batteries; the conductivity, viscosity and stability are the most important assessment parameters. In the literature, one can find several lithium salts such as $\mathrm{LiPF}_{6}, \mathrm{LiBF}_{4}, \mathrm{LiSO}_{3} \mathrm{CF}_{3}$ and $\mathrm{LiC}\left(\mathrm{SO}_{2} \mathrm{CF}_{3}\right)_{3}$ [56] (see Figure 4). Wenige et al. conclude that $\mathrm{LiPF}_{6}$ is the most commonly used lithium salt in lithium-ion batteries and it has a high conductivity against other electrolytes [56]. However, during charging, organic solvent forms a SEI layer with the graphite based anode, which decreases the conductivity of the system. Moreover, lithium ions cannot be used with aqueous electrolyte because lithium ions react with it and form lithium hydroxide. The electric conductivity of organic $\mathrm{LiPF}_{6}$ electrolyte is 10 to 1000 times lower than aqueous electrolytes as in nickel-metal hydride and lead-acid batteries. 
Figure 4. Comparison of various electrolytes for lithium-ion batteries based on conductivity [56].

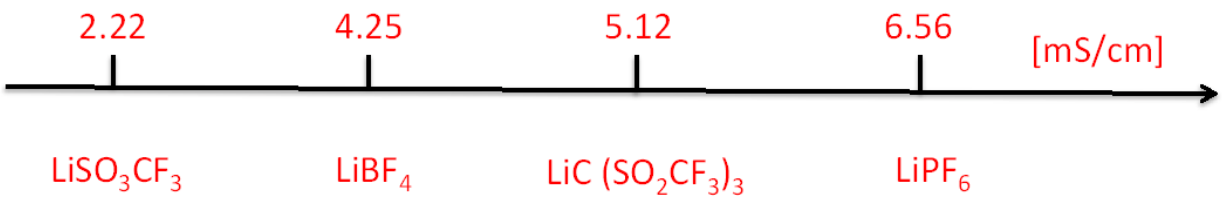

In the framework of this research, the general characteristics of 25 commercial lithium-ion battery cell types of various brands, shapes and capacities from 2.3 to 90 Ah have been investigated and compared to the performances of nickel-metal hydride battery cells, lead-acid, and EDLCs (see Tables 3-6).

The examined parameters are the energy density, charge and discharge capabilities at different current rates, power capabilities and self-discharge. According to the Hybrid Pulse Power Characterization Test, the batteries behaviour in function of state of charge and current rates have been analyzed and a new lithium-ion battery model is proposed.

Table 3. Specifications studied lithium-ion brands.

\begin{tabular}{ccccc}
\hline Battery brand & Rated capacity [Ah] & Nominal voltage [V] & Shape & Chemistry \\
\hline A & 2.3 & 3.3 & Cylindrical & LFP \\
B & 10 & 3.3 & Cylindrical & LFP \\
C & 18 & 3.3 & Cylindrical & LFP \\
D & 3.5 & 3.3 & Cylindrical & LFP \\
E & 2.5 & 3.3 & Cylindrical & LFP \\
F & 11 & 3.3 & Cylindrical & LFP \\
G & 30 & 3.3 & Prismatic & LFP \\
H & 45 & 3.3 & Prismatic & LFP \\
I & 90 & 3.3 & Prismatic & LFP \\
J & 40 & 3.3 & Prismatic & LFP \\
K & 10 & 3.3 & Prismatic & LFP \\
L & 7 & 3.3 & Pouch & LFP \\
M & 14 & 3.3 & Pouch & LFP \\
N & 11 & 3.3 & Pouch & LFP \\
O & 45 & 3.3 & Pouch & LFP \\
P & 45 & 3.3 & Pouch & LFP \\
Q & 20 & 2.2 & Pouch & LTO \\
R & 15 & 2.2 & Pouch & LTO \\
S & 27 & 3.7 & Cylindrical & NCA \\
T & 25 & 3.7 & Pouch & NMC \\
U & 12 & 3.7 & Pouch & NMC \\
V & 70 & 3.7 & Pouch & NMC \\
W & 5.7 & 3.7 & Pouch & NMC \\
Y & 40 & 3.7 & Pouch & NMC \\
X & 3.2 & 3.7 & Pouch & NMC \\
\hline
\end{tabular}


Table 4. Specifications studied VRLA batteries.

\begin{tabular}{cccc}
\hline Battery brand & Rated capacity [Ah] & Nominal voltage [V] & Shape \\
\hline A & 8 & 12 & Cylindrical \\
B & 8.5 & 12 & Prismatic \\
C & 57 & 12 & Prismatic \\
D & 17 & 12 & Prismatic \\
E & 51 & 12 & Prismatic \\
F & 50 & 12 & Prismatic \\
G & 60 & 12 & Prismatic \\
H & 70 & 12 & Prismatic \\
I & 42 & 12 & Prismatic \\
\hline
\end{tabular}

Table 5. Specifications studied nickel-metal hydride.

\begin{tabular}{cccc}
\hline Battery brand & Rated capacity [Ah] & Nominal voltage [V] & Shape \\
\hline A & 30 & 1.2 & Prismatic \\
B & 11 & 1.2 & Cylindrical \\
C & 3 & 1.2 & Cylindrical \\
D & 3 & 1.2 & Cylindrical \\
E & 10 & 1.2 & Cylindrical \\
\hline
\end{tabular}

Table 6. Specifications studied EDLCs.

\begin{tabular}{cccc}
\hline EDLC brand & Rated capacity $[\mathbf{F}]$ & Nominal voltage $[\mathbf{V}]$ & Shape \\
\hline A & 3000 & 2.7 & Cylindrical \\
B & 3000 & 2.7 & Cylindrical \\
C & 3000 & 2.7 & Cylindrical \\
D & 2600 & 2.7 & Cylindrical \\
E & 1500 & 2.7 & Cylindrical \\
F & 600 & 2.5 & Cylindrical \\
G & 450 & 2.5 & Cylindrical \\
\hline
\end{tabular}

Furthermore, this research compares the different battery design concepts such as cylindrical, prismatic and pouch cells as presented in Figure 5. The investigated aspects are the most critical local temperature development and the needed requirements for a battery pack system.

Figure 5. Different lithium-ion battery design concepts.
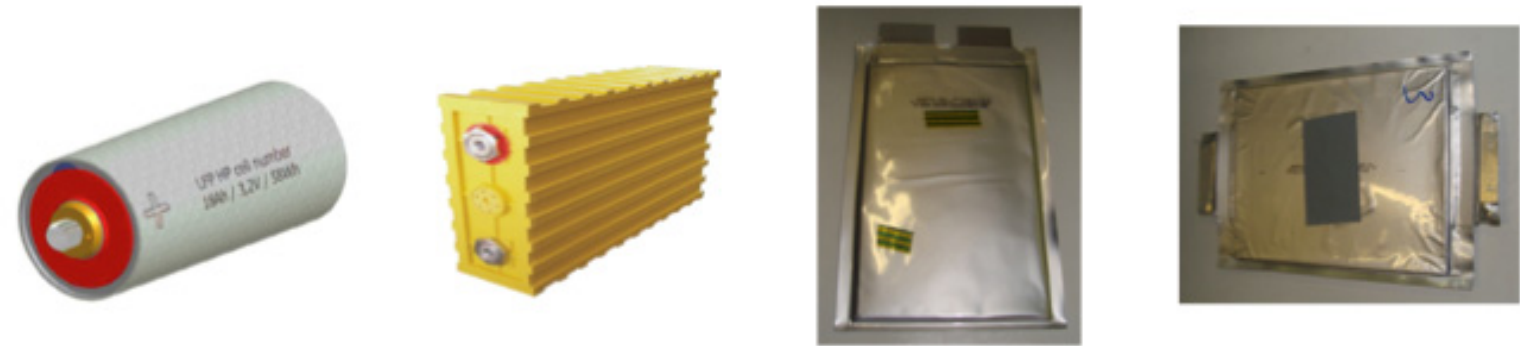
In order to be able to compare the abilities of these energy storage devices in PHEVs, the U.S. Battery Advanced Consortium, Electric Power Research Institute (EPRI) and Sloan Automotive Laboratory at the Massachusetts Institute of Technology (MIT) [6,57,58] as listed in Table 7 will be used. Then these objectives will be compared against the goals that have been defined in the framework of the European project SuperLIB: Advanced Dual-Cell Battery Concept for Battery Electric Vehicles [59]. Here, it should be underlined that the battery cells will be analyzed based on "black-box" approach. This means that the cells will not be investigated on the electrode level as usually done by chemists.

Table 7. Plug-in Hybrid Electric Vehicle requirements [6,57-59].

\begin{tabular}{ccccc}
\hline & USABC & EPRI & MIT & SuperLIB \\
\hline Range [miles] & $10 / 40$ & $20 / 60$ & 30 & 40 \\
CD operation & AER & Blended & AER & AER \\
Energy density [Wh/kg] & $93 / 142$ & $37 / 59$ & 133 & $>75$ \\
Power density [W/kg], 10 s pulse & $833 / 383$ & $340 / 328$ & 733 & 775 \\
Cycle life (charge depleting), $(\% \mathrm{DoD})$ & $5000(70)$ & $2400 / 1400(80)$ & $2500(70)$ & $2000(90)$ \\
Cycle life (charge sustaining) & 300.000 & 200.000 & 175.000 & $?$ \\
Cost price [\$/kW] & $300 / 200$ & - & 320 & $?$ \\
Vehicle mass [kg] & $1950 / 1600$ & $1664 / 1782$ & 1350 & 1300 \\
Battery mass [kg] & $60 / 120$ & $159 / 302$ & 60 & 250 \\
\hline
\end{tabular}

The assessment and characterization of RESS is a hard task. It can be performed at different ways as proposed by the references [21,25,34-49]. As mentioned before, these methodologies aim to analyze limited specific parameters. In this study, a new characterization method is presented in Figure 6 based on the described tests sequences in [60,61]. As we notice, the methodology contains all the essential characterizations and performance tests at room temperature (RT). According to this way, also all relevant parameters can be derived for modeling of battery technology or type.

Figure 6. Characterization methodology.

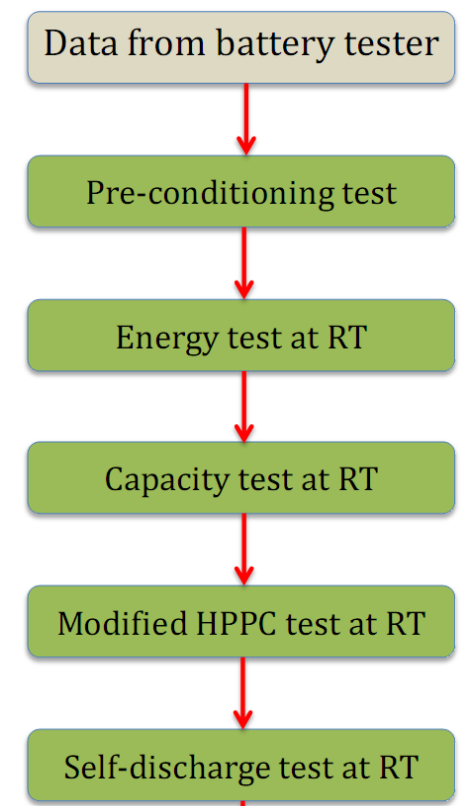




\section{Results and Discussion}

\subsection{Energy Density}

In Figures 7 and 8 the results of the dynamic discharge performance tests are mapped out. As we can observe in Figure 7, the energy density of lithium nickel manganese cobalt oxide cathode cells is in the range of $70-160 \mathrm{Wh} / \mathrm{kg}$, compared to $70-110 \mathrm{Wh} / \mathrm{kg}$ for lithium ion phosphate cathode cells. In the same figure, we can recognize that $\mathrm{LiNiMnCoO}_{2}$ cathode cells also could be optimized for hybrid applications rather than battery electric vehicles, as is the case for battery brand W-NMC, where the energy density is about $71 \mathrm{Wh} / \mathrm{kg}$.

Figure 7 illustrates that the energy density of lithium nickel cobalt aluminum cathode cells is less favourable: $90 \mathrm{Wh} / \mathrm{kg}$. However, in [21] is documented that the energy density of such chemistry is comparable to the $\mathrm{LiNiMnCoO}_{2}$ based cells. Furthermore, the results show that the energy density of lithium titanate anode cells is relatively low: $70 \mathrm{Wh} / \mathrm{kg}$. The latter point is due to the lower nominal voltage, which is about $2.2 \mathrm{~V}$. While the high energy abilities of $\mathrm{LiNiMnCoO}_{2}$ are the results of the high nominal voltage and high specific capacity as presented in Table 3.

According to the preliminarily results, we can conclude that only $\mathrm{LiNiMnCoO}_{2}$ based cells can meet all listed requirements. While the other mentioned chemistries including nickel-metal hydride fulfill the EPRI goal of $37 \mathrm{Wh} / \mathrm{kg}$. Figure 8 reveals that the abilities of lead-acid batteries (23-28 Wh/kg) are very limited compared to other battery technologies.

Figure 7. Energy density versus energy efficiency of various lithium-ion chemistries on cell level.

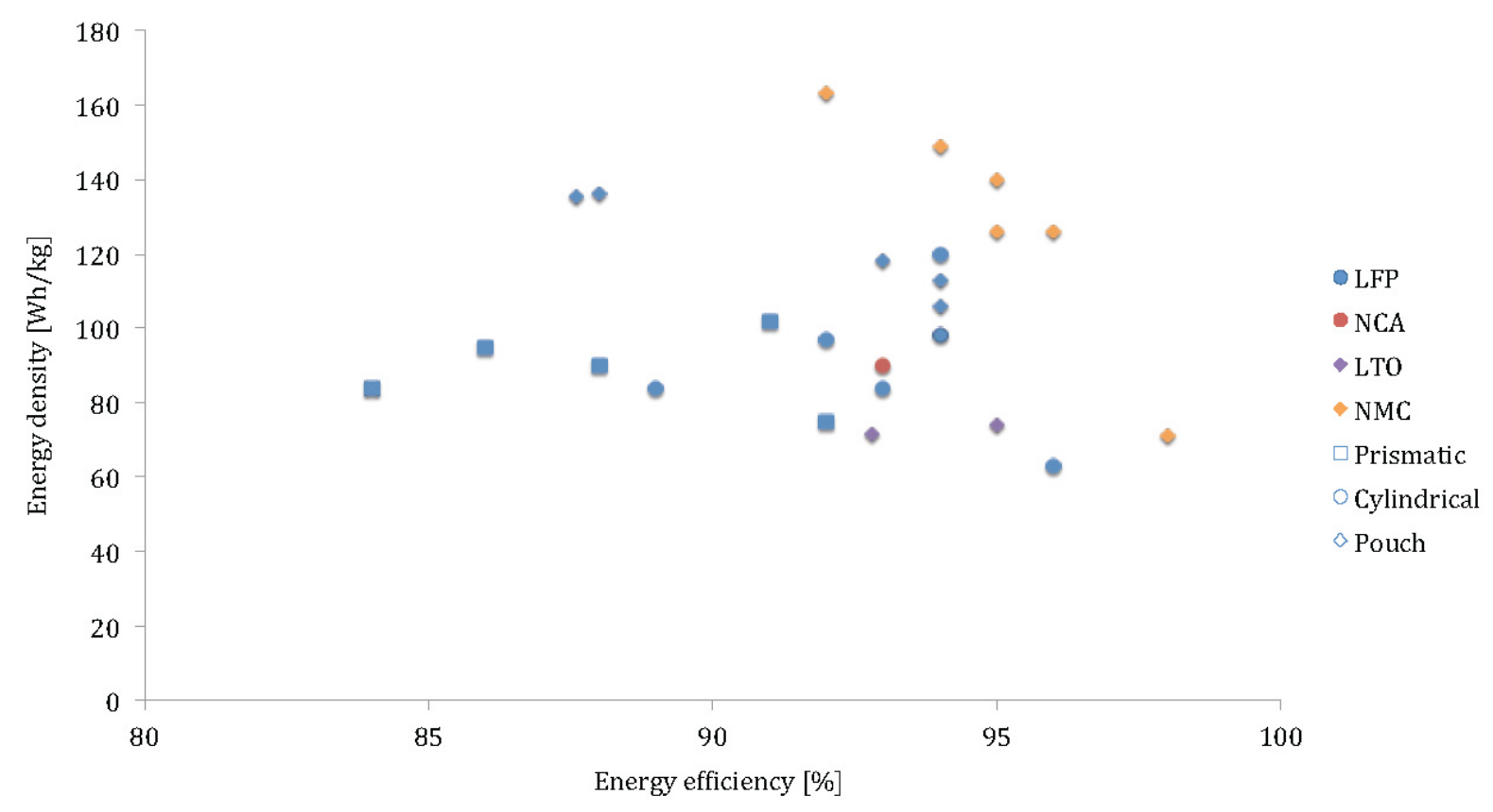


Figure 8. Energy density versus energy efficiency of nickel based, lead-acid batteries and EDLCs on cell level.

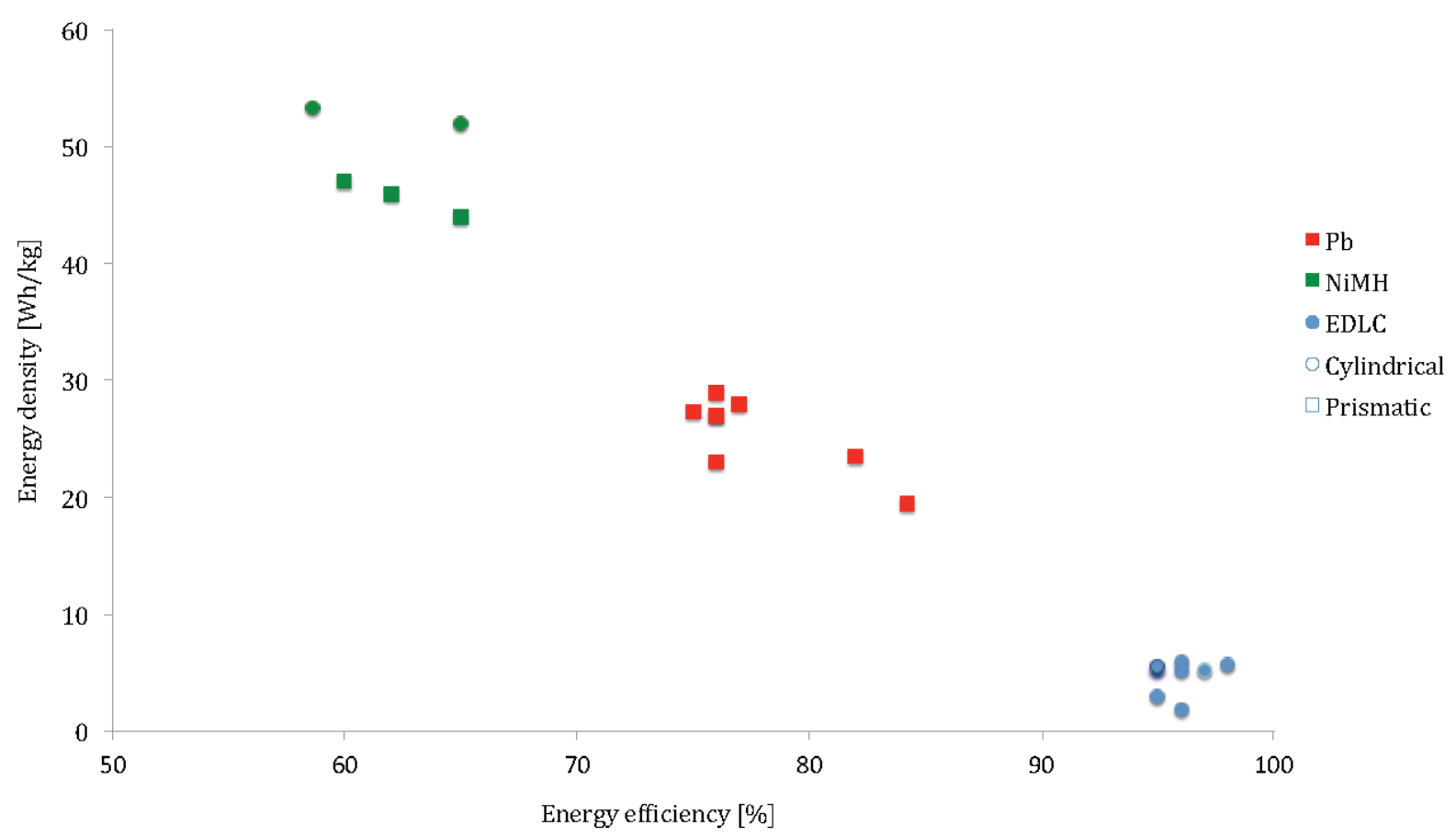

Here, it should be underlined that EPRI objectives in the terms of energy are rather conservative due to heavier battery mass assumptions (159-320 kg) compared to USABC and MIT (60-120 kg). However SuperLiB objectives regarding the battery mass are more stringent. The total battery mass is estimated on $250 \mathrm{~kg}$ including enclosure, interconnection between the cells, heating and cooling systems, where the USABC, MIT and EPRI requirements assume an additional weight of 20 up to $30 \%$ of the battery cells.

According to the specifications of European batteries and EIG Batteries packs, only the mass of the enclosure, interconnections and BMS are considered about $15 \%-20 \%$ of the total battery cells weight $[62,63]$. With adding heating and cooling systems, the energy density at the battery pack level will be significantly lower.

In Figure 8 the energy performances of EDLCs are presented and compared. The values vary between 2 and $6 \mathrm{Wh} / \mathrm{kg}$. The obtained results indicate the poor energy abilities of activated carbon-carbon EDLCs. This result to the fact these systems can not be used a main energy source as they are in fact designed as power devices.

Here it should be noted that EDLCs are energy storage systems sized to meet high power applications. The mechanisms inside the EDLCs are totally different of the redox and lithium-ion batteries. As it is presented in Figure 9 an EDLC consists of two porous carbons based electrodes, an organic electrolyte and a separator. Unlike to conventional capacitors, there is no reaction between the electrolyte and electrode surface. By applying a voltage, the ions in the electrolyte attract with the opposite charge of the electrode [64,65]. Thus, a double-layer will be formed at each electrode. Here it should be underlined that each double-layer can be assumed as a conventional capacitor. The both layers correspond to two capacitors in series, where the total capacitance is equal to $\mathrm{C}_{\mathrm{EDLC}}=\left(1 / \mathrm{C}_{\mathrm{cap} 1}+1 / \mathrm{C}_{\mathrm{cap} 2}\right)^{-1}$. But due to the porous electrode surface area $\mathrm{A}$ and the short distance $\mathrm{d}$, 
the obtained capacitance is much higher than conventional capacitors as expressed in the following equation:

$$
\mathrm{C}_{\mathrm{EDLC}}=\varepsilon \cdot \varepsilon_{\mathrm{o}} \frac{\mathbf{A}}{\mathbf{d}}
$$

where $\varepsilon$ and $\varepsilon_{0}$ represent the relative permittivity of the dielectric material and permittivity of the free space, respectively. The specific capacitance of one electrode is about $100 \mathrm{~F} / \mathrm{g}$, which is assumed based on $1000 \mathrm{~m}^{2} / \mathrm{g}$ for the surface area of the electrode and $10 \mu \mathrm{F} / \mathrm{cm}^{2}$ for the double-layer [65].

From Figure 9 we can notice that the internal resistance will be much smaller than conventional capacitors. Thus the energy efficiency of EDLCs is in the range of $95 \%-98 \%$, as illustrated in Figure 8.

Figure 9. EDLC working mechanisms [16].

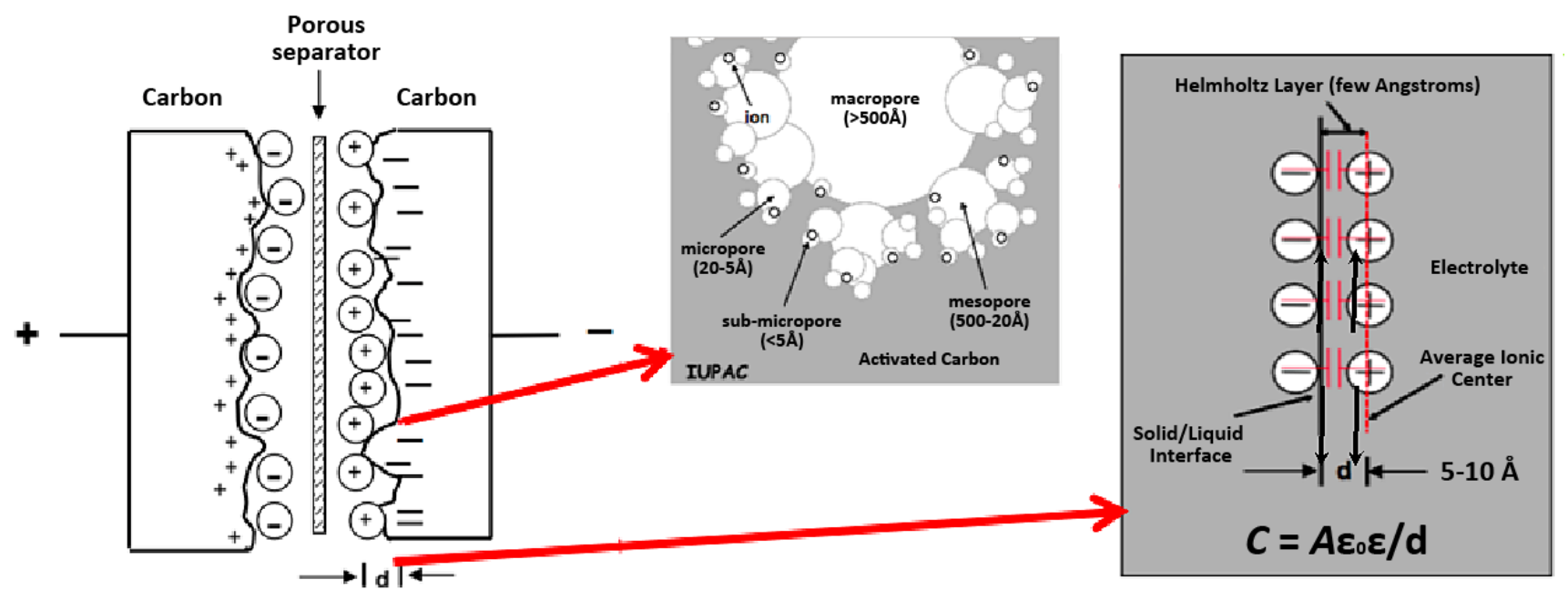

On the other hand, the MIT requirements are based on the charge depleting driving mode, where the internal combustion engine is assisting the battery system; in the USABC and EPRI, however the energy content is assumed according to the All Electric Mode, whereby the battery is only the active energy source until $70 \%$ and $80 \%$ DoD has been reached for USABC and EPRI, respectively.

In order to limit energy losses and temperature rising inside the battery system, the energy efficiency of such battery should be very high. In Figure 7 we observe that the energy efficiency of the lithium ion batteries is in the range of $86 \%-98 \%$ against $74 \%$ for nickel metal hydride, $75 \%-85 \%$ for lead-acid and $65 \%$ for nickel cadmium battery.

Here it should be noted that the nickel based and lead-acid battery cells have been charged and discharged at the same way as the lithium-ion batteries. The charge current was $1 \mathrm{I}_{t}$ and the discharge current was based on the DDP test as reported in [60,61].

Figure 7 shows that the lithium-ion pouch battery design concept has better characteristics (93\%-98\%) compared to $89 \%-93 \%$ and $86 \%-91 \%$ for cylindrical and prismatic battery cells, respectively. The better performances of pouch cells are due to the bigger surface area. Moreover, this cell design is very thin, which results that the temperature gradient inside the battery is negligible, so the heat development easily can be dissipated compared with prismatic and cylindrical cells [66].

At the battery pack level, about 100 battery cells are connected in series such as in Nissan Leaf and 
Opel Ampera [67,68]. The Battery Management System (BMS) monitors the voltages of individual cells and temperature at cell/module level to prevent damage and identify defective cells or modules. As discussed in [69,70], all type of lithium-ion batteries can be damaged and in the worst case scenario may explode. As documented in [69], there are various battery balancing system topologies (such as passive and active) that can be used in function of the variation between the cells or modules in a battery pack.

Figure 10 represents the standard deviation of the tested battery brands. The presented variations have been calculated based on 5 cells for each battery type. As one can see, most of the tested batteries indicate a variation in the range of $0.3 \%-0.4 \%$. However, the batteries O-LFP and P-LFP show a dispersion of about $2.2 \%-2.3 \%$, which results that a heavy BMS topology may be required.

Figure 10. Standard variation of tested lithium-ion battery brands.

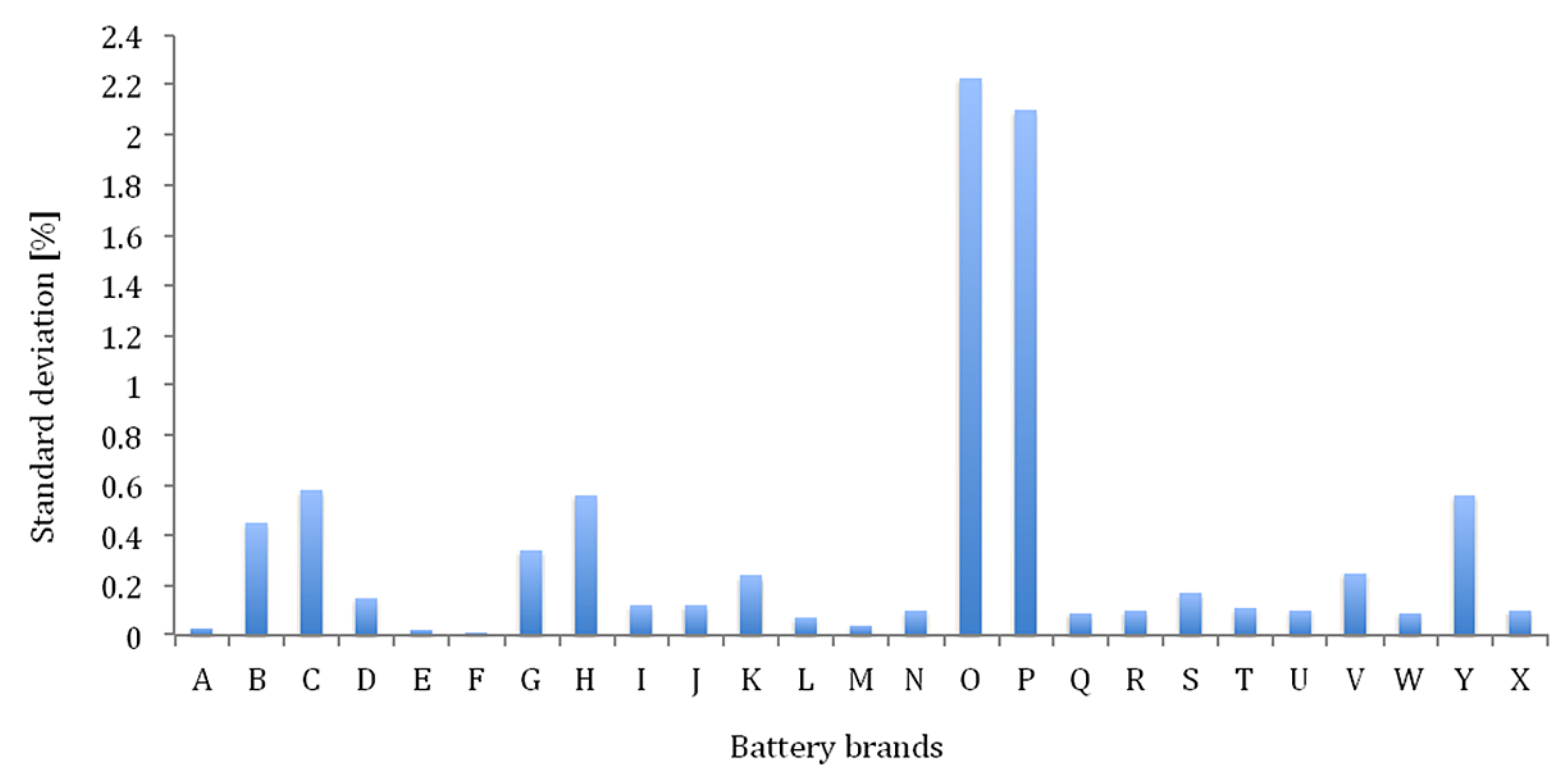

\subsection{Rate Capabilities}

\subsubsection{Discharge}

In plug-in hybrid electric vehicles, the power and energy densities are the most relevant key issues for assessment of the static parameters. However, there are many variables that should be considered for evaluation of an appropriate energy storage system. Some of these variables are the impact of the working temperature and discharge rate currents on the battery performances. Based on such test, the RESS performances among the whole depth of discharge (DoD) window can be analyzed. Furthermore, the thermal behaviour of the RESS can be mapped out in function of the applied current. In this section, only the current rates abilities have been considered. The temperature impact will be discussed later.

In the world of battery testing, the capacity test can be considered as one of the key test regimes, allowing one to map out the battery behaviour at different discharge current rates.

In Figure 11 an example is presented of the capacity test at $0.33 \mathrm{I}_{t}, 1 \mathrm{I}_{t}, 2 \mathrm{I}_{t}, 5 \mathrm{I}_{t}$ and $10 \mathrm{I}_{\mathrm{t}}$. As we can see in Figure 12 the delivered capacity is almost equal, independent of the applied current rates. However, 
the results of the various lithium-ion brands in Figure 12 reveal that this characteristic does not occur for all batteries such as for the battery types with high energy density: G-LFP, H-LFP, O-LFP, P-LFP, T-NMC, V-NMC and X-NMC (see Figure 12). This is due to the fact that these batteries have been dimensioned for a specific working envelope $\left(0.33 \mathrm{I}_{\mathrm{t}}-3 \mathrm{I}_{\mathrm{t}}\right)$. Unlike the high power based battery cells, the supplied capacity is less independent of the imposed current rates. The latter one can be explained by the geometry of the used electrodes. In high power applications, such as in HEVs, the batteries should be able to be charged and discharged very quickly for acceleration and braking phases. This can be made by construction thin electrodes with a large surface area. So, the lithium ions can be ionized in the electrolyte, transferred from one electrode and intercalated into another. While the energy based batteries have a low surface area to volume ratio due to the thicker electrodes for storing much amount quantities of charge. According to Tahil, it is the volume that determines the storage capacity and surface area the maximum discharge rate [71]. According to the Equation (2), we can conclude that the thicker electrodes increase the internal resistance of the battery cell:

$$
R=\rho \cdot \frac{l}{A}
$$

Figure 11. Discharge behaviour of battery brand A-LFP (high power).

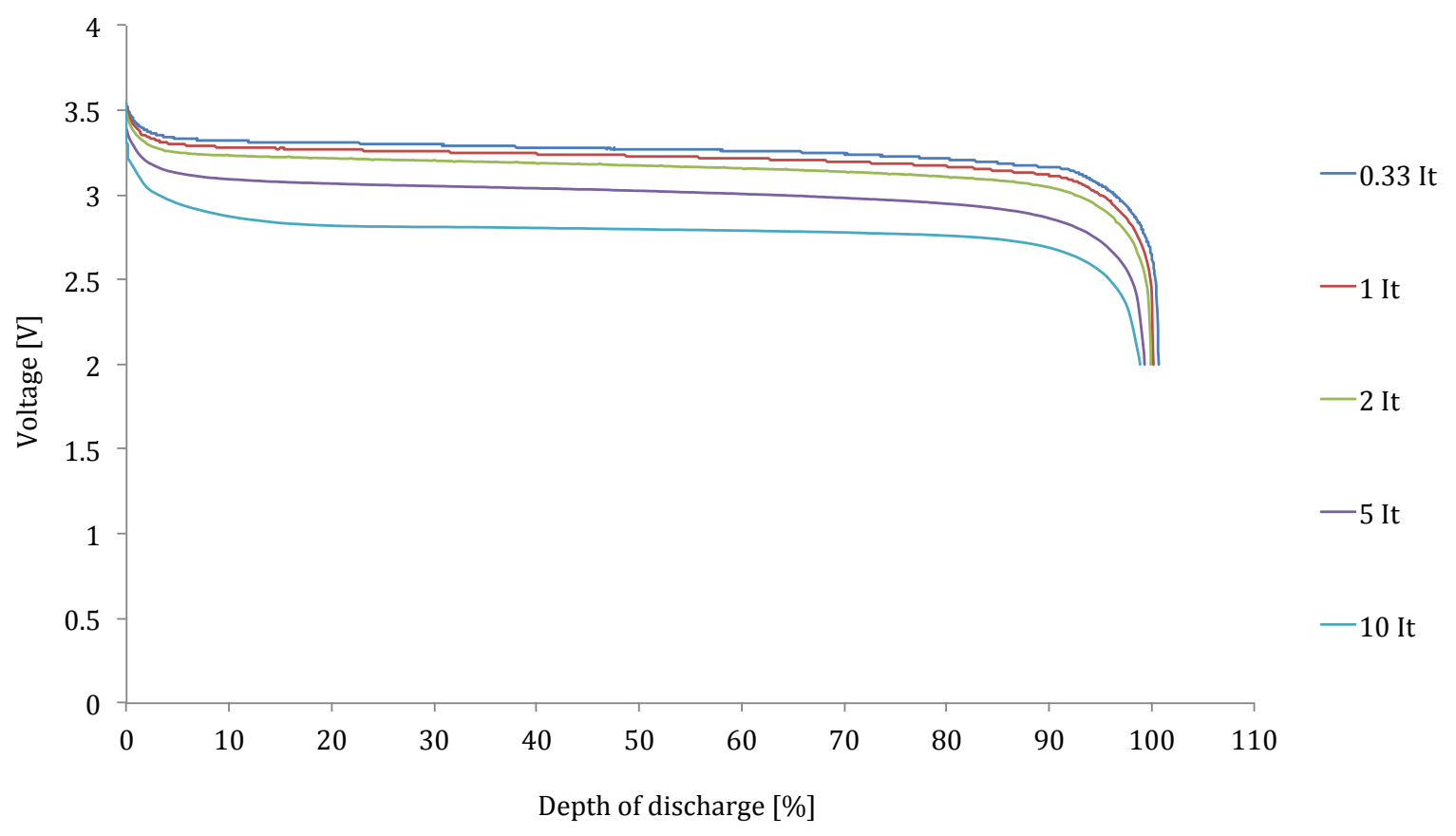


Figure 12. Discharge capabilities at different current rates.

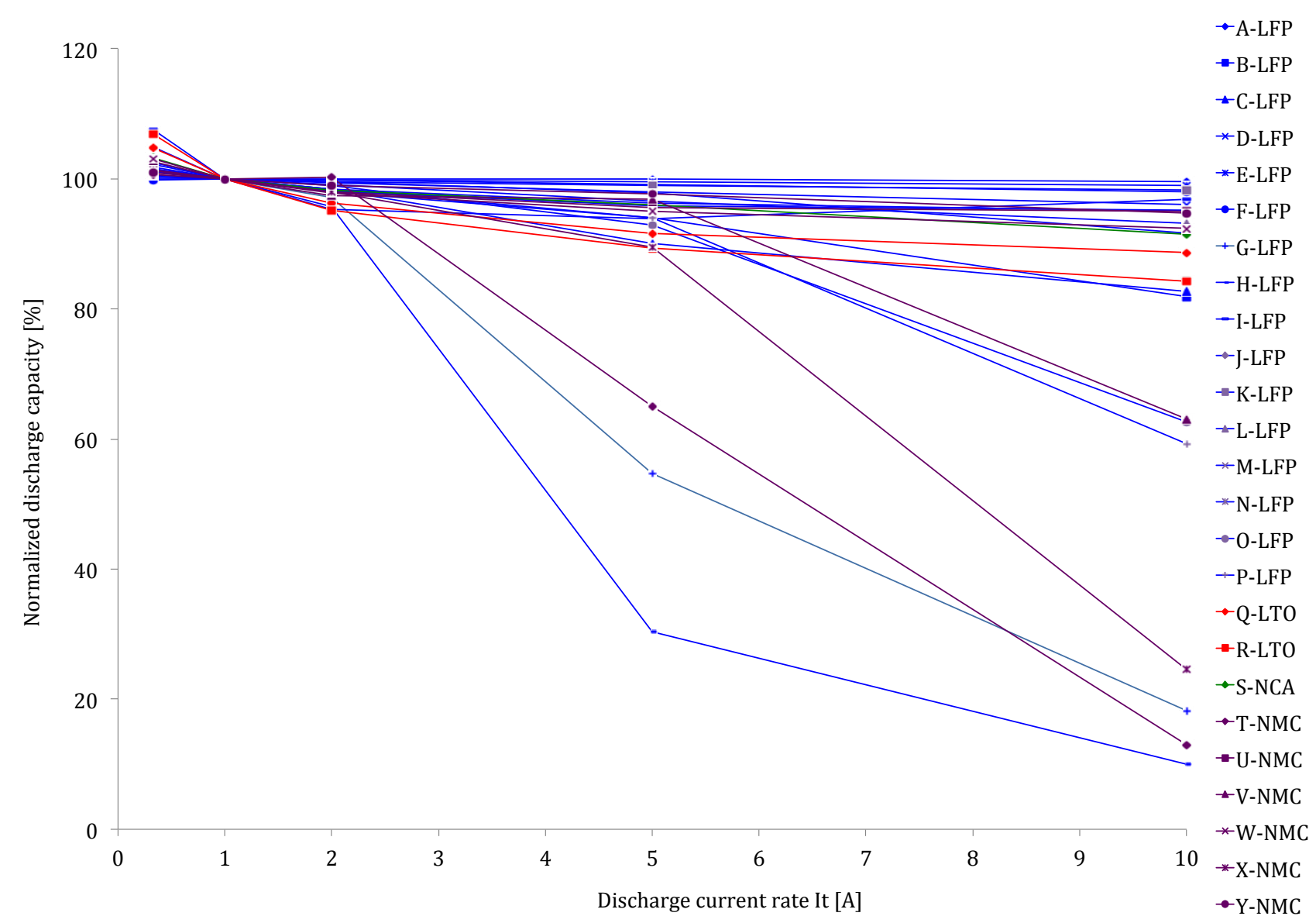

For high energy batteries, the voltage drop due to the ohmic resistance can be considered as the major parameter for the poor discharge rate capabilities as it is presented for in Figure 13.

Figure 13. Discharge behaviour of battery brand O-LFP (high energy).

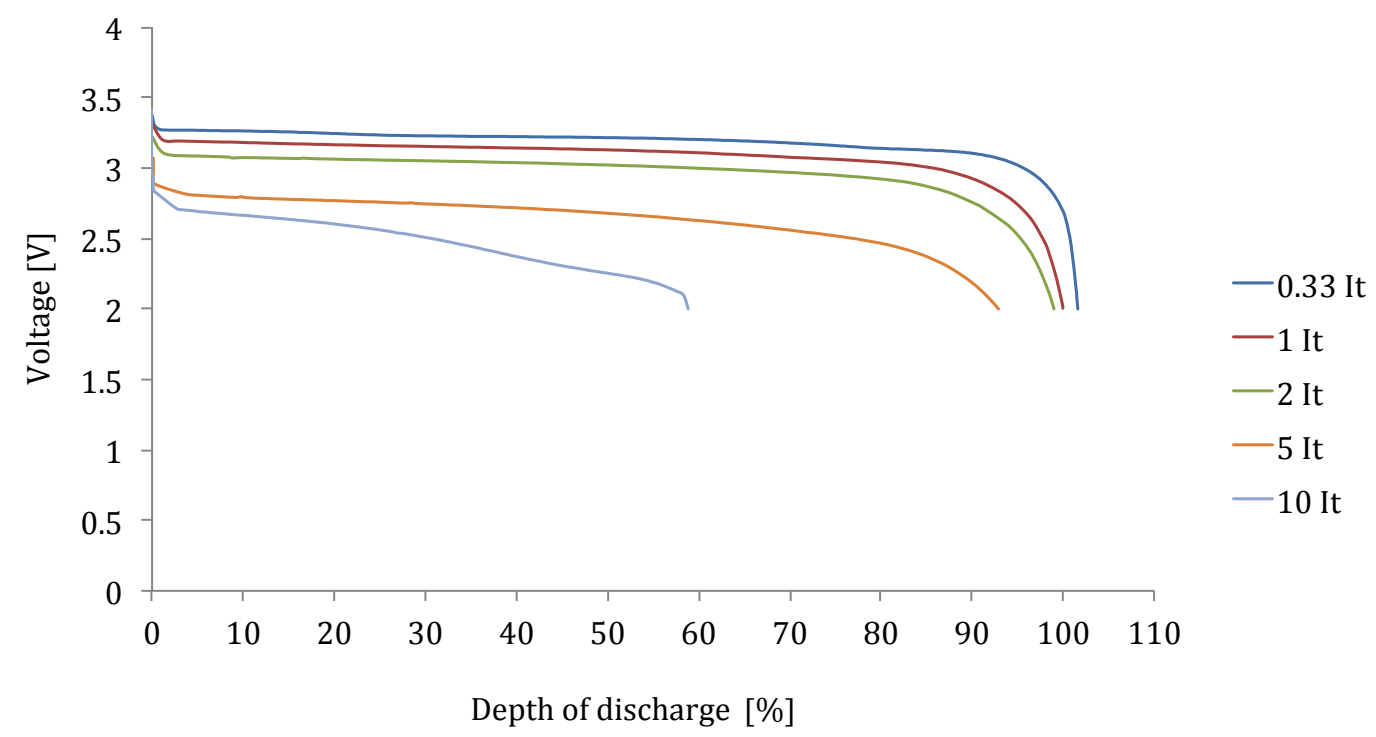

However, the capacity fade in batteries can be further related to the ohmic activation and concentration polarization phenomena (see Figure 14). 
The activation polarization occurs when the reactions of the electrodes do not perform perfectly. In order to make this possible, there is a need for some energy.

The effect of the concentration polarization is due to the concentration differences of the reactants at the electrode surface area. At higher current rates, the reactions in the battery cell should proceed very fast and therefore there is less time for the reactants to mix. Thus, a big difference in the concentration increases the internal resistance and energy losses. The influence of all these factors combined with the geometry of the electrodes in the high energy based battery cells result in the fact that battery falls to provide sufficient capacity at high current rates.

Figure 14. Cell polarization in function of current rate [71].

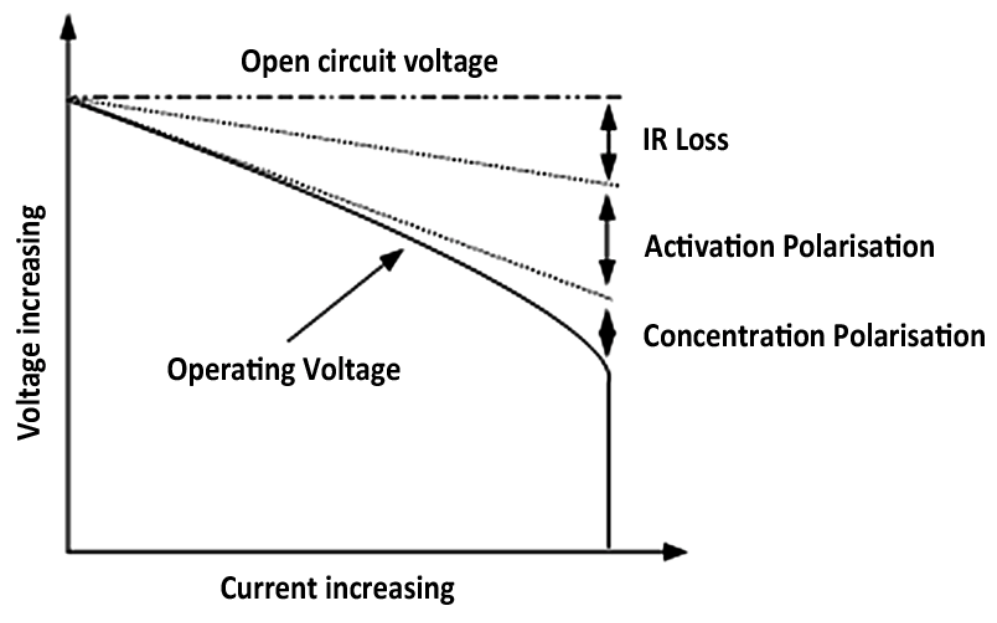

Figure 15. Discharge rate capabilities of the investigated EDLCs.

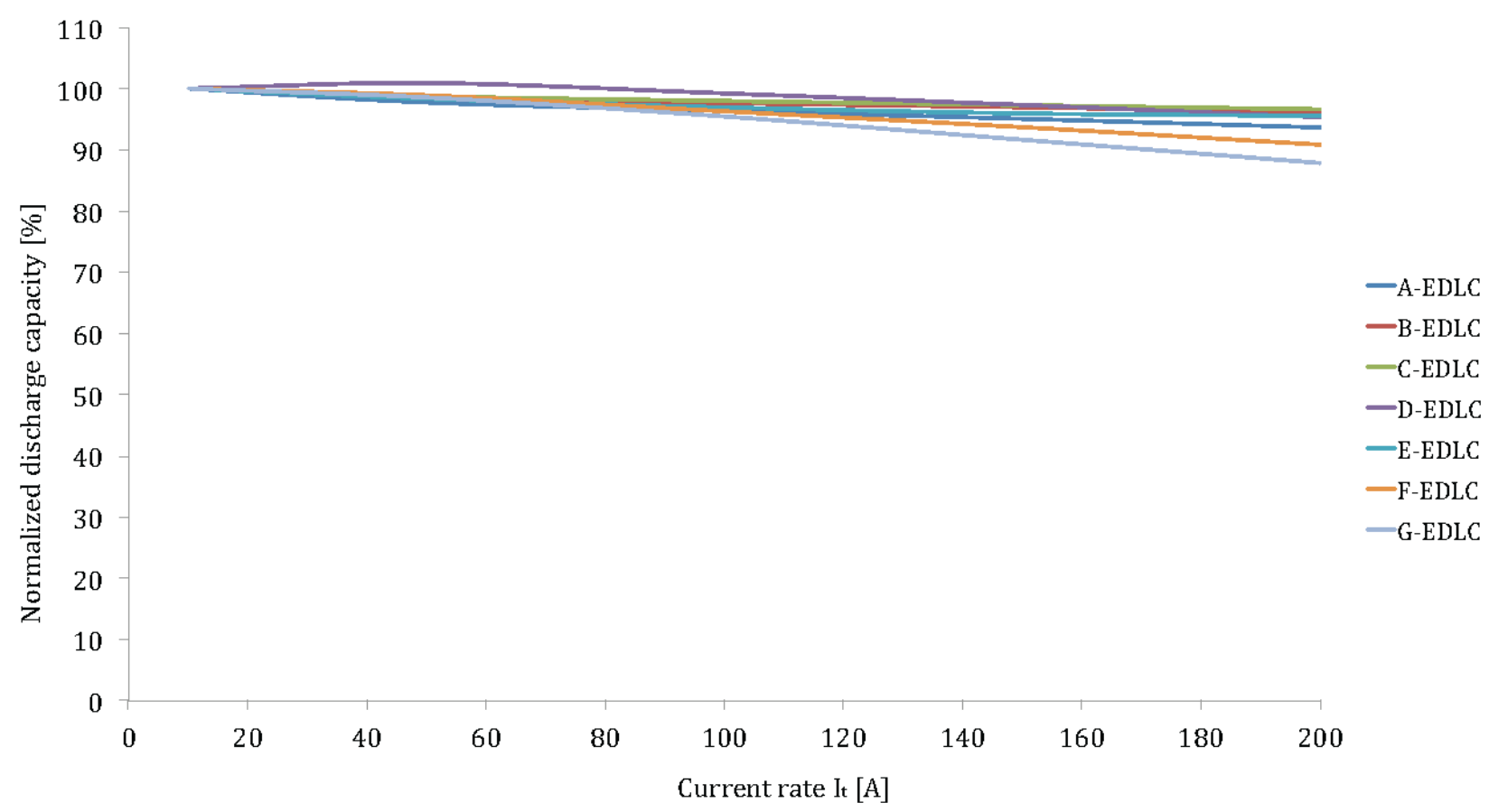

Unlike to lithium-ion batteries, EDLCs do not suffer of the high current rates. The capacity decrease at $200 \mathrm{I}_{\mathrm{t}}$ is in the range of $5 \%-12 \%$ (see Figure 15). This duration is due to the double-layer phenomenon as described before. The internal resistance is much lower and the rate of the reaction is 
much higher, because no chemical reaction occurs.

Based on this test, the Peukert value of each battery technology can be calculated. The Peukert equation is an empirical formula, which approximates how the available capacity of a battery changes according to the rate of discharge as expressed in Equation (3) [72]:

$$
\mathrm{C}_{\mathrm{p}}=\mathrm{T}_{\mathrm{dis}} \cdot \mathrm{I}_{\mathrm{dis}}^{\mathrm{k}}
$$

where $C_{p}$ is the theoretical capacity of the battery expressed in $A h, I_{\text {dis }}$ is the discharge current, $T_{\text {dis }}$ the discharge time and $\mathrm{k}$ is the Peukert constant. This equation shows that at a higher discharge current, there is less capacity available in the battery. The Peukert constant indicates how well a battery performs under continuous heavy discharge current. A value close to 1 indicates that the battery performs well; the higher the value, the more capacity is lost when the battery is discharged at high current. Figure 16 reveals that the Peukert constant for lithium-ion based batteries varies between 1 and 1.09. Particularly the battery cells with high rated capacity such as H-LFP, O-LFP, P-LFP and $\mathrm{X}-\mathrm{NMC}$, indicate the highest values. Figure 16 exhibits the superior performances of lithium-ion technology against lead-acid and nickel-metal hydride batteries. The Peukert constant for the latter technologies is much higher between 1.08 and1.15 with exception of VRLA brand B-VRLA that shows high value 1.28. Here it should be underlined that the Peukert constant has been derived by discharging the batteries at $1 \mathrm{I}_{\mathrm{t}}$ and $2 \mathrm{I}_{\mathrm{t}}$ until $100 \%$ DoD.

Figure 16. Peukert constant of various lithium-ion battery brands.

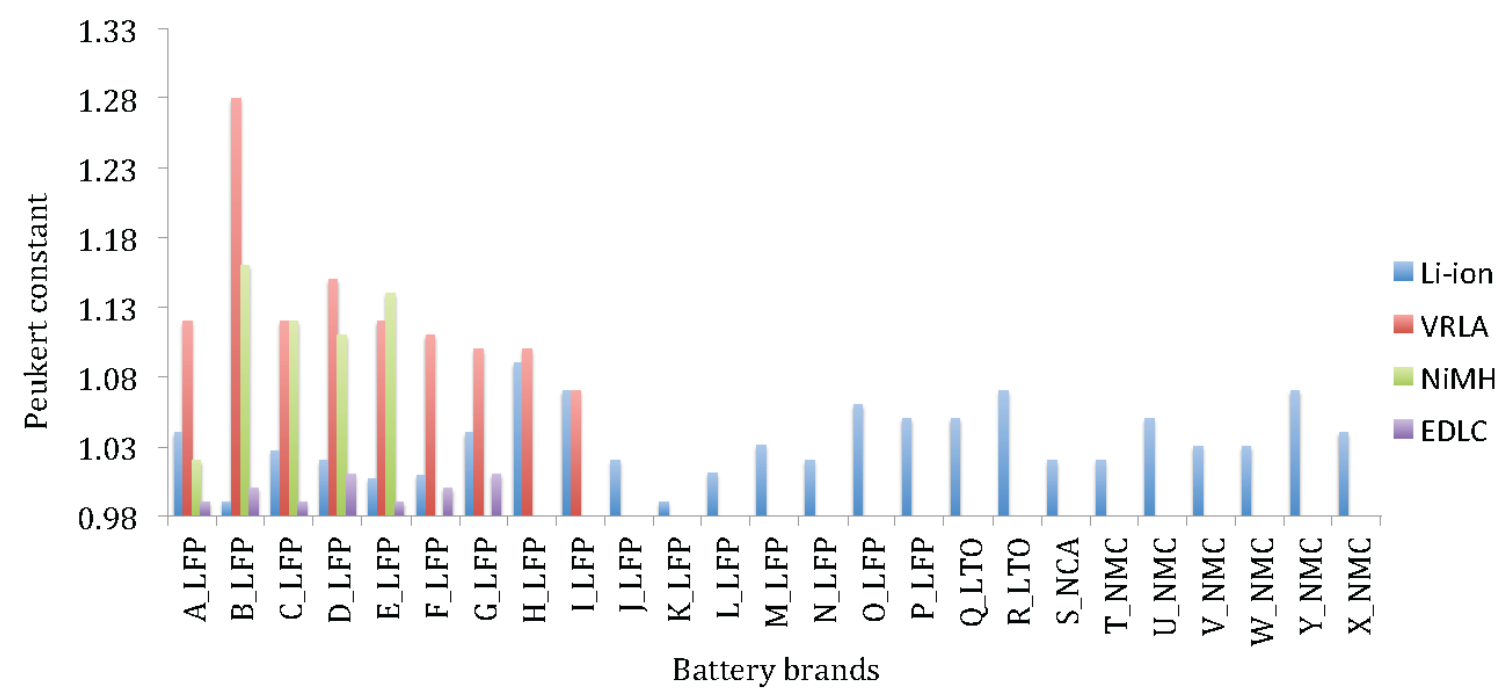

Furthermore, we can conclude that the current rates have a considerable high impact on the battery performances. This aspect should be taken into account particularly for modeling issues, where the battery models should be related to the current rate.

Figure 17 illustrates the discharge curves of the various lithium-ion chemistries, battery technologies and EDLC. Here, we recognize that the voltage shape for lithium iron phosphate based battery cells is different from the lithium titanate oxide, lithium nickel manganese cobalt oxide and lithium nickel cobalt aluminum oxide based cells. This result to the fact that the state of charge estimation based on voltage reading is much easier for NMC, NCA and LTO based battery cells than for LFP, which needs a well-dedicated prediction technique. 
Figure 17. Voltage versus depth of discharge.

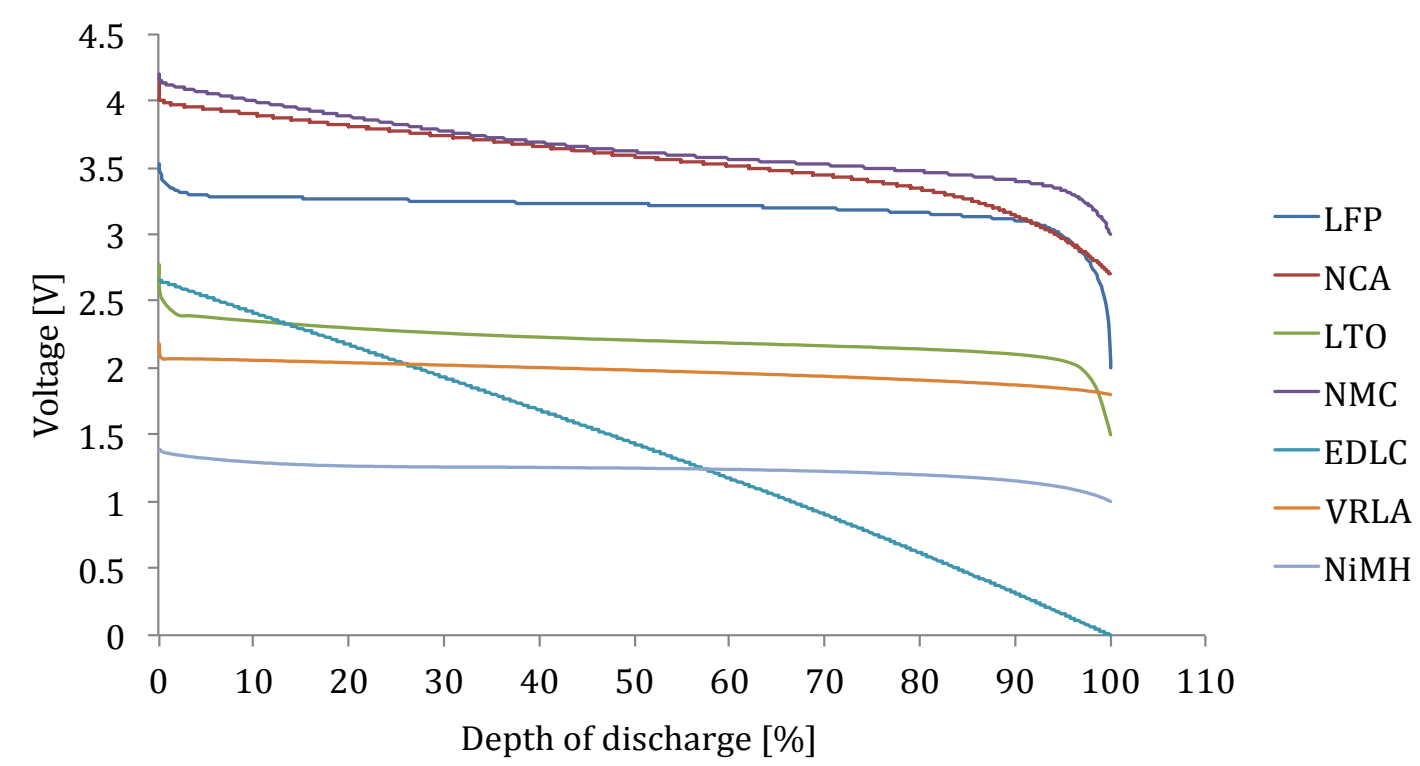

From the discharge capacity test, we assume that the battery is completely empty when the minimal voltage has been reached $\left(\mathrm{V}_{0}\right)$. However, at the end of the test, the voltage increases until it has reached the steady state condition $\left(\mathrm{V}_{2}\right)$. This issue can be achieved after 30 minutes depending of the current rates. From Figure 18, we observe that the battery still has some additional capacity due to recovery phenomena. This means that the battery cell has still some capacity that can be provided at low currents. It should be noted that the recovery voltage raises the more the current rate increases. So, in order to include this phenomenon into a mathematical relationship, the following equation can be used:

$$
C_{b}=C_{\text {initial }}-\int \frac{I_{\text {bat }} \cdot T_{s}}{C .3600}\left(\frac{I_{\text {bat }}}{I_{\text {nom }}}\right)^{n-1}-C_{\text {recov }}(\mathrm{I})
$$

where $\mathrm{I}_{\mathrm{bat}}$ and $\mathrm{T}_{\mathrm{s}}$ represent the employed battery current and the sampling time. While $\mathrm{I}_{\text {nom }}$ and $\mathrm{n}$ stand for the nominal current and Peukert number. For lead-acid batteries, the nominal voltage depends on the manufacturer's specifications. In some cases, the manufacturer specifies a $\mathrm{C}_{5}, \mathrm{C}_{10}$ or $\mathrm{C}_{20}$. The number in this notation stands in for the discharge time in hours. As example the nominal current of a battery with a capacity of $57 \mathrm{Ah}\left(\mathrm{C}_{5}\right)$ is $11.4 \mathrm{~A}$. However, for lithium-ion batteries, the nominal current is $1 \mathrm{I}_{\mathrm{t}}$.

One of the challenges in battery modeling is the reflecting of the different relationships inside a battery. In order to represents this characteristic by a mathematical way, the least-square method (LSM) has been used:

$$
\operatorname{LSM}=\sum_{\mathrm{i}=1}^{\mathrm{i}=\mathrm{n}}\left[\left(\mathrm{y}_{\text {measurment }}\left(\mathrm{t}_{\mathrm{i}}\right)-\mathrm{y}_{\text {simulated }}\left(\mathrm{t}_{\mathrm{i}}\right)\right]^{2}\right.
$$

According to this method, the logarithmical relationship can be extracted:

$$
\mathrm{V}=\mathrm{a} \cdot \ln (\mathrm{t})+\mathrm{b}
$$

with equation coefficients at 0.33 current rate: a: 0.0808 ; b: 2.7486 . 
Figure 18. Recovery phenomenon of LFP based battery cell (A-LFP).

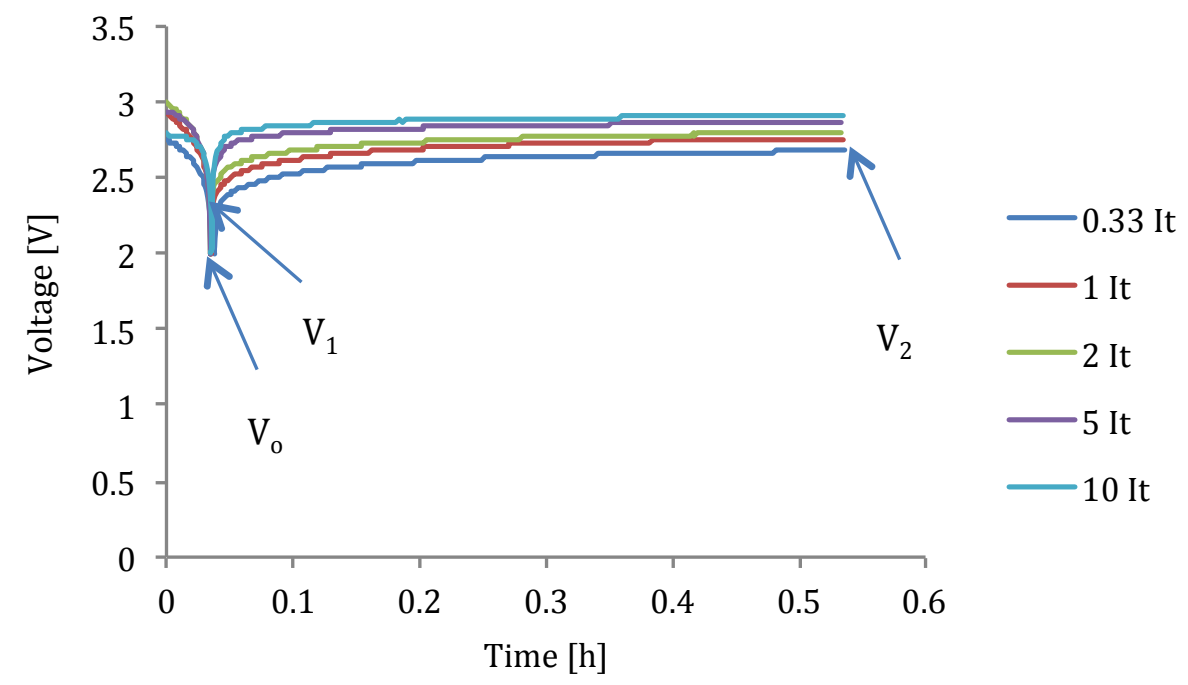

On the other hand, the nonlinear characteristics of a battery become more complex by considering the hysteresis as presented by Figure 19. As we observe, the voltage evolution during charge differs from the discharge. This means that the charge/discharge reactions do not occur identically. In addition, these curves diverge the more the current rates raises.

Figure 19. Hysteresis lithium-ion battery brand A-LFP.

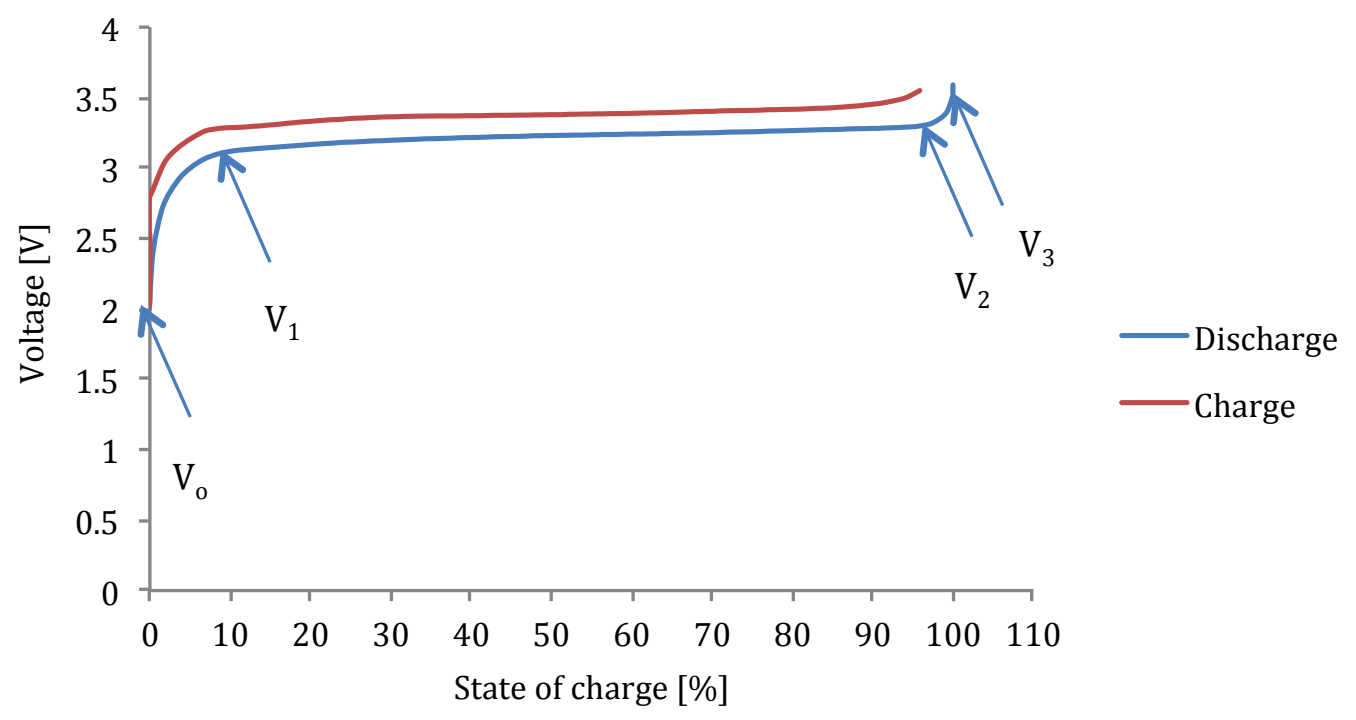

In order to represent this by a mathematical relationships, the relationship between $V_{0}$ and $V_{1}, V_{2}$ and $V_{3}$ can be described by first order model or polynomial equation, where the part between $V_{1}$ and $\mathrm{V}_{2}$ can be considered as a linear equation.

\subsubsection{Charge}

In order to enhance the suitability of the battery technology in PHEV applications, the battery requires, besides good power, energy and energy efficiency performances, also acceptable fast charging capabilities. Most of the commercial battery electric vehicles are typically charged with a 
current of 16 A taken from the grid [73-75]. This means that the charge process for PHEV applications will take several hours (around 6 to 8 ) until the battery has been full charged. Van den Bossche defined three charging speed levels [75]:

- Standard charging $(3.7 \mathrm{~kW})$;

- Semi-fast charging $(7.2 \mathrm{~kW})$;

- Fast charging $(>22 \mathrm{~kW})$;

- Ultra-fast charging up to $250 \mathrm{~kW}$ ).

In [75], it is reported that the charging process of battery typically involves in two phases as it is presented in Figure 20:

- The main charging phase, where the bulk of energy is recharged into the battery;

- The final charge phase, where the battery is conditioned and balanced;

Figure 20. Charging process [75].

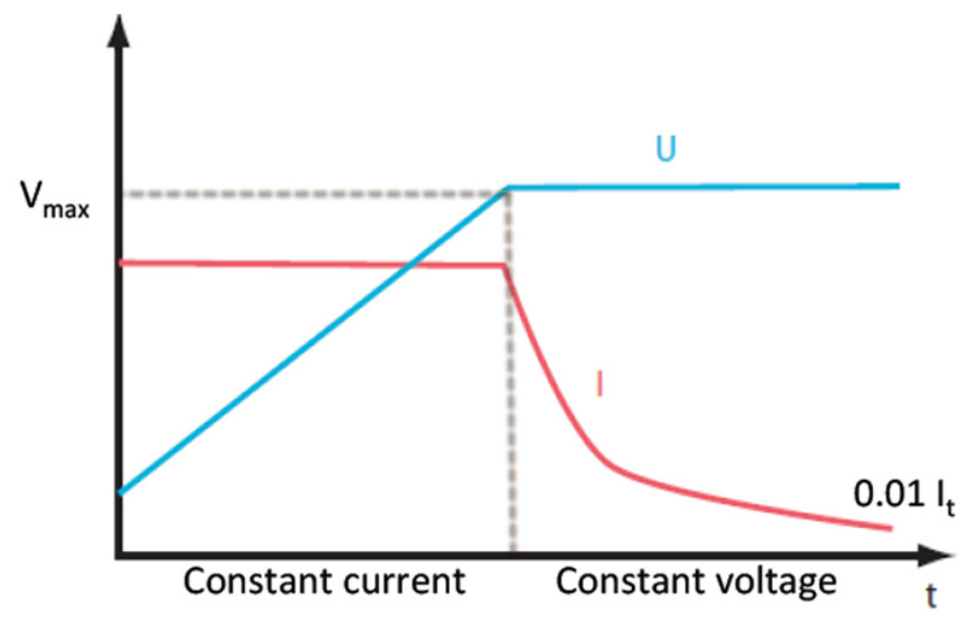

The standard charging mode uses a power level corresponding to the standard power outlets in residential installations. In most European countries, these outlets are rated at $230 \mathrm{~V} / 16 \mathrm{~A}$.

Semi-fast charging mode still makes use of higher power levels still available in residential settings (corresponding to e.g., and electric range) In USA this is called "Level 2" charging. Higher power can be achieved by a high current single phase connection or with three phase connections, $3 \times 400 \mathrm{~V}$, with 16 A per phase yielding up to $11.1 \mathrm{~kW}$ at unity power factor:

$$
\mathrm{P}=\sqrt{3} \times 400 \times 16 \times \cos \propto=11.1 \mathrm{~kW}
$$

This power level also can be increased up to $22.2 \mathrm{~kW}$ by using $32 \mathrm{~A}$ instead of $16 \mathrm{~A}$.

In [75], several power levels for semi-fast charging are reported with the corresponding rated voltage and current. Fast charging uses specific heavy infrastructures for transfer the high power level. Therefore, the power transfer can be performed by d.c. or a.c. connection between the vehicle and the charging post. Fast charging mode is proposed for power levels up to $250 \mathrm{~kW}$ [73]. According to reference [74], an electric vehicle can be charged in less than 10 minutes. 
Several charging modes have been defined in the standard IEC61851-1 [76] and are extensively documented in [76]. In this section, only the main charging phase has been considered at different charge current rates $\left(0.33 \mathrm{I}_{\mathrm{t}}, 1 \mathrm{I}_{\mathrm{t}}, 2 \mathrm{I}_{\mathrm{t}}\right.$ and $\left.5 \mathrm{I}_{\mathrm{t}}\right)$.

Figures 21 and 22 show clearly that lithium-ion batteries have much better performances than lead-acid and nickel-metal hydride based batteries. For most lithium-ion batteries, the stored capacity up to $\mathrm{V}_{\max }$ is almost $80 \%$ at $5 \mathrm{I}_{\mathrm{t}}$. Due to the higher charge current rates, the charge time can be reduced with a factor 10. Thus, the discharge time is less than 1 hour instead of 8 hours as mentioned above. Here, it should be noted that battery cells with high energy, which are designed for PHEVs and BEVS show high performances $(85 \%-100 \%)$ between $1 \mathrm{I}_{\mathrm{t}}$ and $2 \mathrm{I}_{\mathrm{t}}$ but indicate less performances at higher current rates.

By comparing all these lithium-ion chemistries, we can observe that $\mathrm{LiTiO}_{2}$ have the best performances. The normalized stored capacity at the maximum voltage is higher than $90 \%$ independent of the current rates. These results can be explained by the bigger surface area of the anode electrode in $\mathrm{LiTiO}_{2}: 100 \mathrm{~m}^{2} / \mathrm{g}$ compared to $3 \mathrm{~m}^{2} / \mathrm{g}$ for the graphite based electrode in the lithium iron phosphate, lithium nickel manganese cobalt oxide and lithium nickel cobalt aluminum oxide based batteries [77]. The bigger surface area allows moving the electrical charges quickly. Thus, the lithium titanate oxide does not suffer from high current rates.

Then, the charge time during the constant voltage varies between 0.3 and $1.5 \mathrm{~h}$ compared to 5-8 h, typically for lead-acid and nickel-metal hydride technologies.

Figure 21. Charge performances of lithium-ion brands and chemistries.

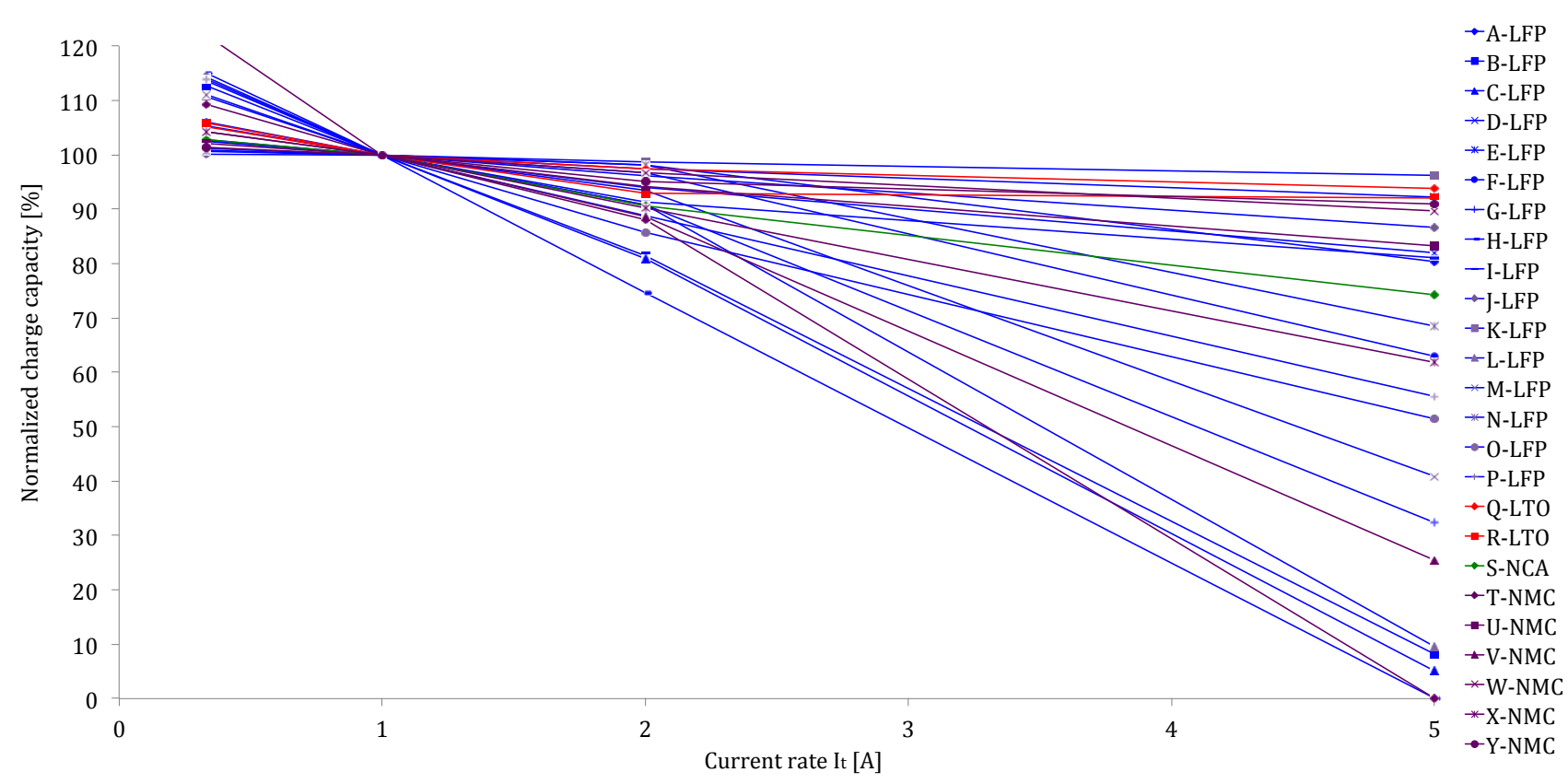


Figure 22. Charge performances of VRLA and NiMH battery technologies at different current rates.

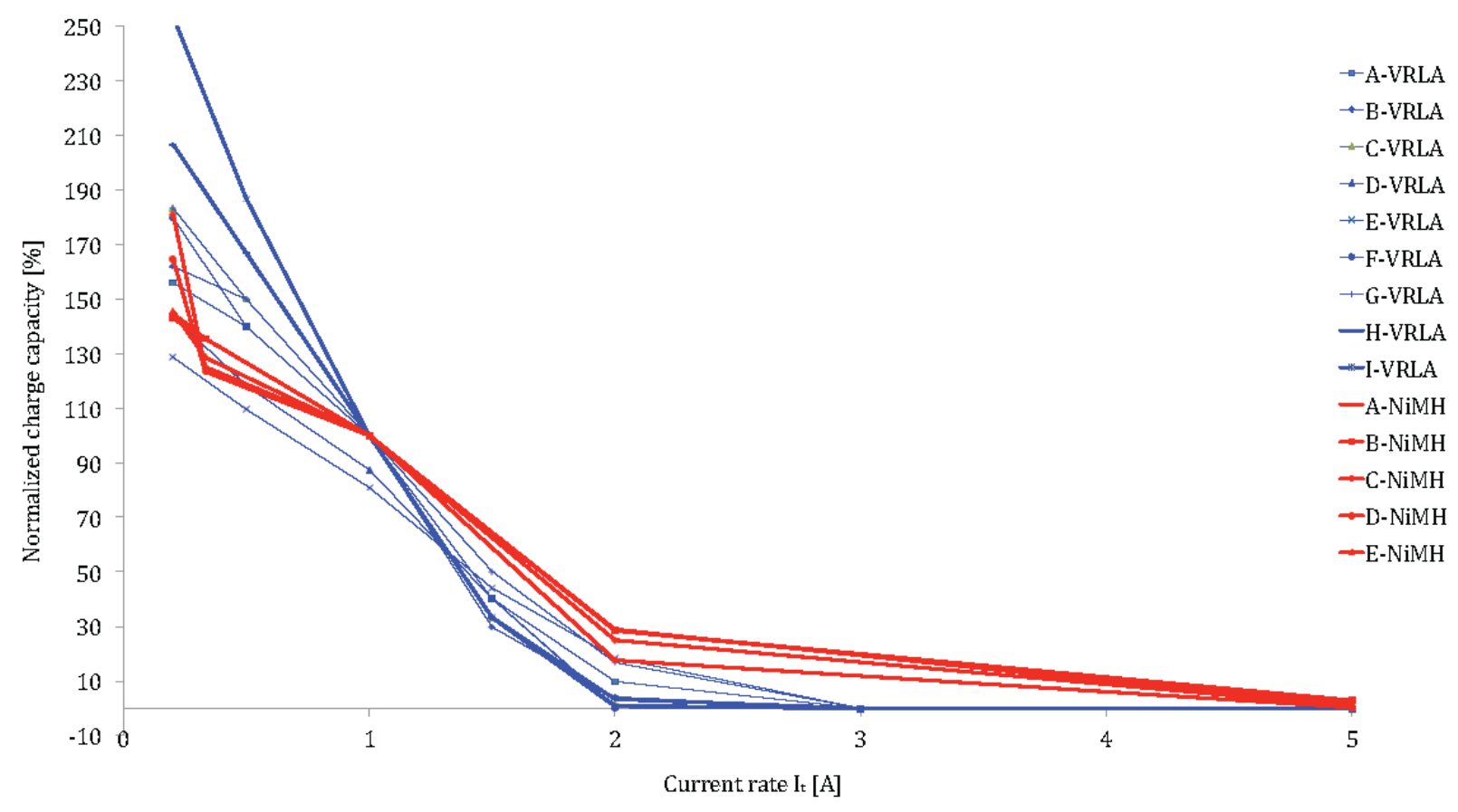

However, the impact of fast charging on the cycle life of batteries is a factor that could not be examined from a single fast charging test.

In modeling and assessment of battery technologies, the state of charge estimation also can be considered as a key issue. The most used technique in circulation is the SoC-VoC relationship. However, this technique is not applicable due to the flat voltage duration between $80 \%$ and $30 \%$ SoC. Thus, the estimation in this region becomes very difficult. Another known technique is based on the ampere-hour counting as presented by Equation (8):

$$
\text { SoC }=C_{\text {initial }}- \begin{cases}\int i_{b}(t) d t & I>0 \\ \int-i_{b}(t) d t & I<0\end{cases}
$$

But this technique exhibits some drawbacks since it does not take into account high current behavior and the Peukert phenomenon. However, the battery in reality is continuously subjecting various stress parameters, such as current rates, depth of discharge, temperature and cycle life. In order to overcome these problems, in [78] an empirical estimation of state of charge is documented [see Equation (9)]. In this equation, the Peukert number is included. But, the Peukert number here is assumed as constant. However, this parameter varies in function of many other parameters (will be contributed in the future research article). Furthermore, the Equation (9) only reflects the battery behaviour during the discharge phase. Equation 10 proposes a modified version whereby; the influence of the recuperated energy is included. In Figure 22, we recognized that the evolution of the stored capacity in function of current rate is not logarithmical as we have observed during discharge phase, but linear. Thus, instead of a Peukert number, a coulomb efficiency $E_{f f}$ has been defined as presented by Equation (10). 


$$
\begin{gathered}
\text { SoC }=1-\frac{\mathrm{I}_{\text {bat }} \mathrm{T}_{\mathrm{s}}}{\mathrm{C} .3600}\left(\frac{\mathrm{I}_{\text {bat }}}{\mathrm{I}_{\text {nom }}}\right)^{\mathrm{n}-1} \\
\text { SoC }=1- \begin{cases}\frac{\mathrm{I}_{\text {bat }} \mathrm{T}_{\mathrm{s}}}{\mathrm{C} .3600}\left(\frac{\mathrm{I}_{\text {bat }}}{\mathrm{I}_{\text {nom }}}\right)^{\mathrm{n}-1} & \text { if } \mathrm{I}_{\text {bat }}>0 \\
-\left[\mathrm{Eff}\left(\mathrm{I}_{\text {bat }}\right) \cdot \int \mathrm{I}_{\mathrm{bat}} \cdot \mathrm{dt}\right] & \text { if } \mathrm{I}_{\text {bat }}<0\end{cases} \\
\mathrm{E}_{\mathrm{ff}}=\frac{\mathrm{C}_{\text {stored }}}{\mathrm{C}_{\text {stored at } 1 \mathrm{It}, 25^{\circ} \mathrm{C}}}
\end{gathered}
$$

\subsubsection{Power Performances}

In this test, the batteries discharge and charge power during 10 seconds pulses are determined as a function of depth of discharge at different current rates. The batteries have been charged at $1 \mathrm{I}_{\mathrm{t}}$ rate and then discharged at the same current rate till the desired DoD level. The pulse power tests are made at $80 \%, 65 \%, 50 \% 35 \%$ and $20 \%$ SoC as presented in Figure 23. The power capabilities of the batteries were determined by the open-circuit voltage and current as presented by Equations (12) and (13). In this study current pulses $\left(0.33 \mathrm{I}_{\mathrm{t}} 1 \mathrm{I}_{\mathrm{t}} 2 \mathrm{I}_{\mathrm{t}} 5 \mathrm{I}_{\mathrm{t}} 10 \mathrm{I}_{\mathrm{t}}, 15 \mathrm{I}_{\mathrm{t}}\right.$ and $\mathrm{I}_{\max }$ have been selected:

$$
\begin{aligned}
& P_{\text {ch }}\left(\frac{\mathrm{W}}{\mathrm{kg}}\right)=\frac{\mathrm{V}_{\text {dis }} \mathrm{I}}{\mathrm{m}} \\
& \mathrm{P}_{\text {dis }}\left(\frac{\mathrm{W}}{\mathrm{kg}}\right)=\frac{\mathrm{V}_{\mathrm{ch}} \cdot \mathrm{I}}{\mathrm{m}}
\end{aligned}
$$

In the above equations, $\mathrm{V}_{\text {dis }}$ and $\mathrm{V}_{\mathrm{ch}}$ represent the voltage drop at the end of each pulse during discharge and charge respectively. I and $\mathrm{m}$ stand in for imposed current and the battery cell mass.

Figure 23. Extended HPPC pulse at different SoC level and state of charge.

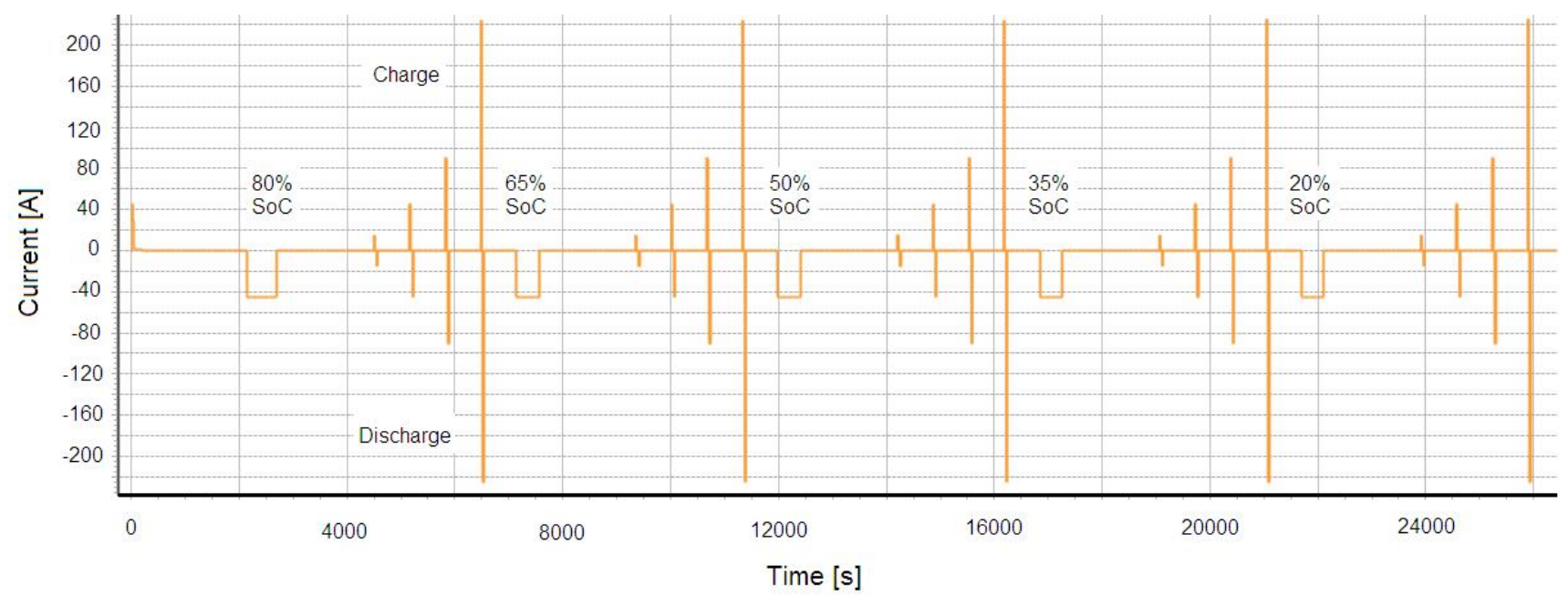

Figure 24 confirms the favorable discharge performances of lithium-ion technology against nickel-metal hydride and VRLA particularly as shown in Figure 25 . The power density of the analyzed lithium-ion battery types varies between 300 and $2400 \mathrm{~W} / \mathrm{kg}$ compared to $200-400 \mathrm{~W} / \mathrm{kg}$ for nickel-metal hydride and 90-120 W/kg for lead-acid batteries. Compared to Figure 8, the power varies 
in a wide range and is strongly dependent of state of charge. The high values over $700 \mathrm{~W} / \mathrm{kg}$ show that these batteries are optimized for high power applications. The high power batteries show a more complex relationship between $\mathrm{SoC}$ and power, rather than a linear one. This makes the development of a battery model more complicated.

Figure 24. Power capabilities of lithium-ion batteries at different SoC levels.

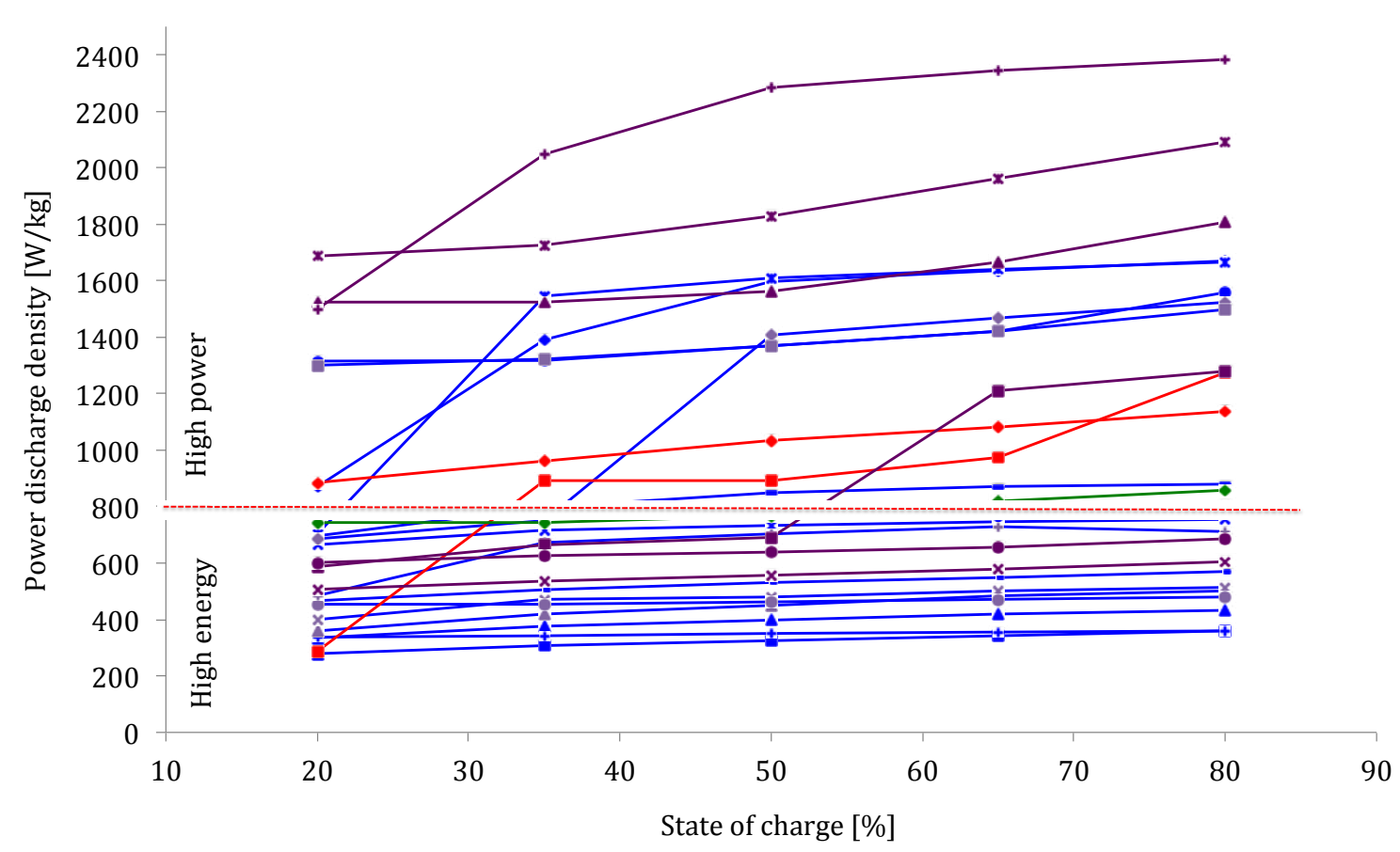

$$
\begin{aligned}
& \rightarrow \text { A-LFP } \\
& \text {-B-LFP } \\
& \triangle \mathrm{C}-\mathrm{LFP} \\
& \text { *D-LFP } \\
& \text { *E-LFP } \\
& \text {-F-LFP } \\
& \text {-G-LFP } \\
& \text {-H-LFP } \\
& \text {-I-LFP } \\
& \rightarrow \text {-LFP } \\
& \text {-K-LFP } \\
& \rightarrow-L-L F P \\
& \text { *M-LFP } \\
& \rightarrow \text { N-LFP } \\
& \rightarrow 0-L F P \\
& \text {-P-LFP } \\
& \rightarrow \text { Q-LTO } \\
& - \text { R-LTO } \\
& \rightarrow \text { S-NCA } \\
& \rightarrow \text { T-NMC } \\
& \text {-U-NMC } \\
& \text { *V-NMC } \\
& \text {-W-NMC } \\
& \begin{array}{l}
-\mathrm{X}-\mathrm{NMC} \\
-\mathrm{Y}-\mathrm{NMC}
\end{array}
\end{aligned}
$$

Figure 25. Power capabilities of nickel-metal hydride and lead-acid battery technologies.

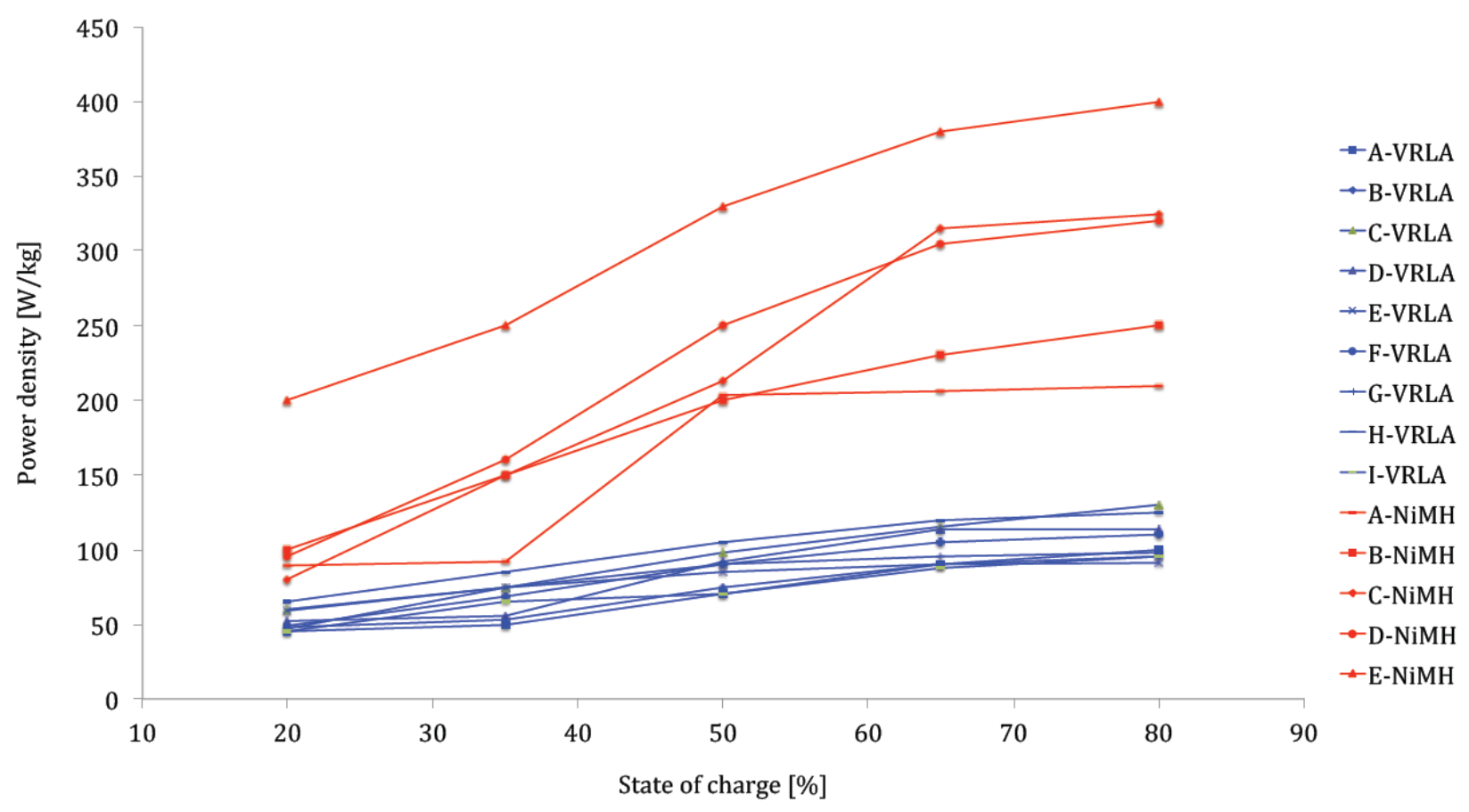


The proposed method based on the standards ISO 12405-1/2 and IEC 62660-1 for comparison of power capabilities is only suitable when the energy efficiency of the pulse, which is strongly depending of the current rate, will not be taken into account [79-81]. Thus for an appropriate comparison, the energy efficiency of the pulse should be considered. Burke et al. specified that the energy efficiency for lithium-ion technology should be around $90 \%$ in order to keep efficiency high and to limit the temperature rising in the battery pack [21]. The energy efficiency of the pulse can be determined at different ways. In [21] Burke proposed to use the open circuit voltage and resistance as function of state of charge as presented by Equation (14):

$$
P_{\text {dis }}\left(\frac{W}{k g}\right)=E_{f f} \cdot\left(1-E_{f f}\right) \cdot \frac{V_{o C^{2}}}{R_{\text {dis }} \cdot m}
$$

where $E_{f f}=\frac{V_{p u l s e}}{V o C}$.

This presented method assumed that the voltage evolution during a pulse is linear. This method can thus be used for systems such as EDLCs, whereby the relationship state of charge-voltage is linear. For batteries, the situation seems more complicated since the system exhibits a voltage drop due to the ohmic resistance of the electrodes, contacts and electrolytes. The voltage decreases exponentially as presented in Figure 26.

Figure 26. Voltage duration during HPPC test.

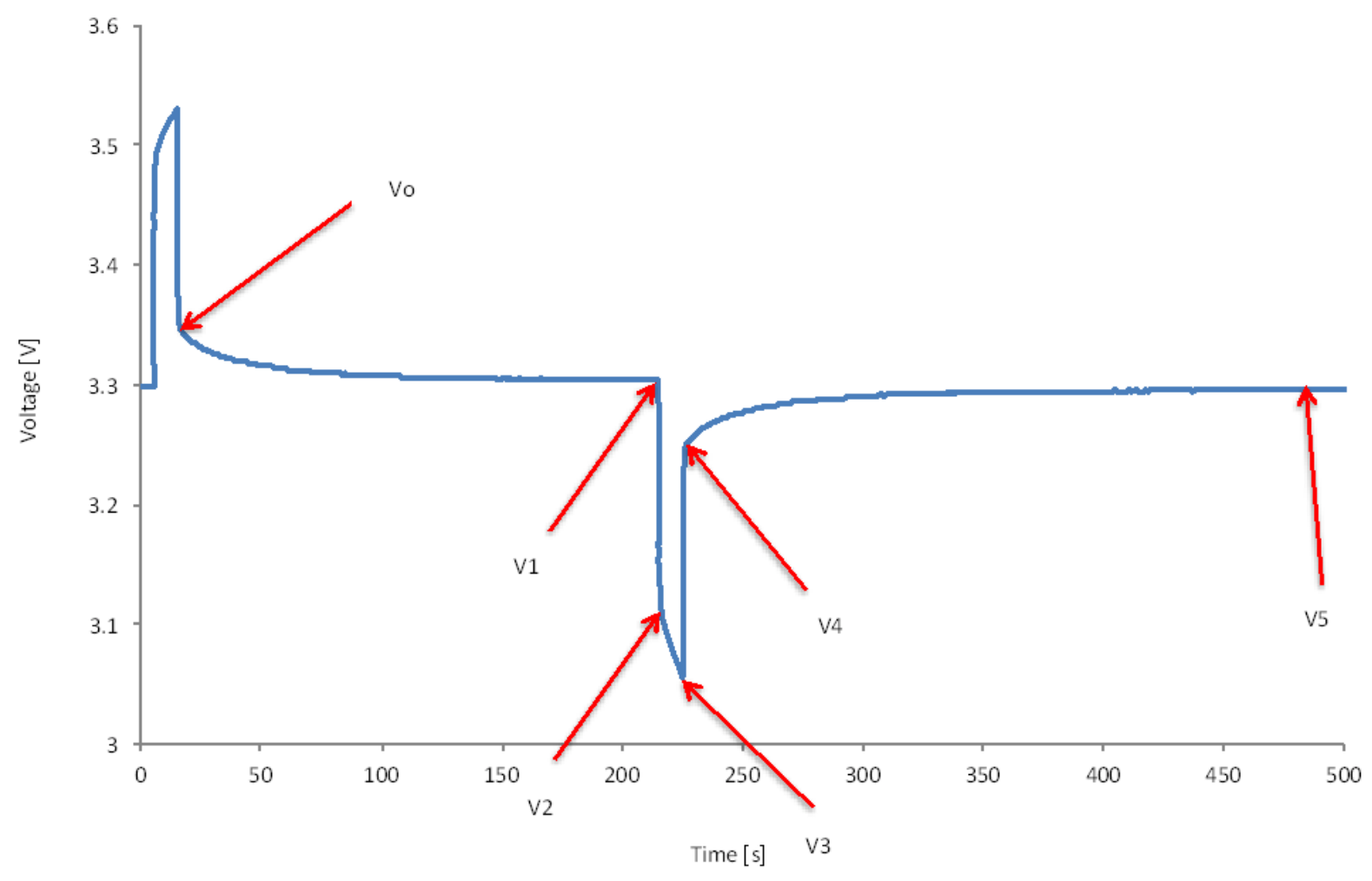

Hereby, we can conclude that the energy efficiency calculation according to Burke is not suitable. The only method that can be used is the ratio of the discharge and charge energy (by using equal pulses) expressed in Wh:

$$
E_{f f}=\frac{W h_{d i s}}{W h_{c h}}
$$


In Figure 27 the power density of the different batteries is presented at $90 \%$ energy efficiency and $50 \%$ SoC. The power density at $90 \%$ pulse efficiency is much lower than in Figure 24 . These results are in line with the results shown in Figure 12.

Due to the bigger surface area the high power battery cells have significantly lower resistance and higher energy efficiency. The high value for battery W-NMC is due to the used anode material, which is hard carbon rather than graphite. Hard carbons are prepared from phenolic resin and can not be graphitized, even when treated at $3000{ }^{\circ} \mathrm{C}$ [82]. On the other hand, materials that can be graphitized by treatment at high temperatures $>200{ }^{\circ} \mathrm{C}$ are termed soft carbons. According to Patterson, hard carbon has a higher specific capacity $480 \mathrm{mAh} / \mathrm{g}$ compared to $370 \mathrm{mAh} / \mathrm{g}$ for graphite and $275 \mathrm{mAh} / \mathrm{h}$ for soft carbon [83]. Due to the fact that the layers for hard carbon are not neatly stacked and non-crystalline, the surface area is much bigger. Moreover, there is no volume change upon lithium ion intercalation against $10 \%$ for used graphite in commercial lithium-ion batteries [83]. This means that the cycleability can be enhanced.

Figure 27. Power density at 50\% SoC and 90\% pulse energy efficiency.

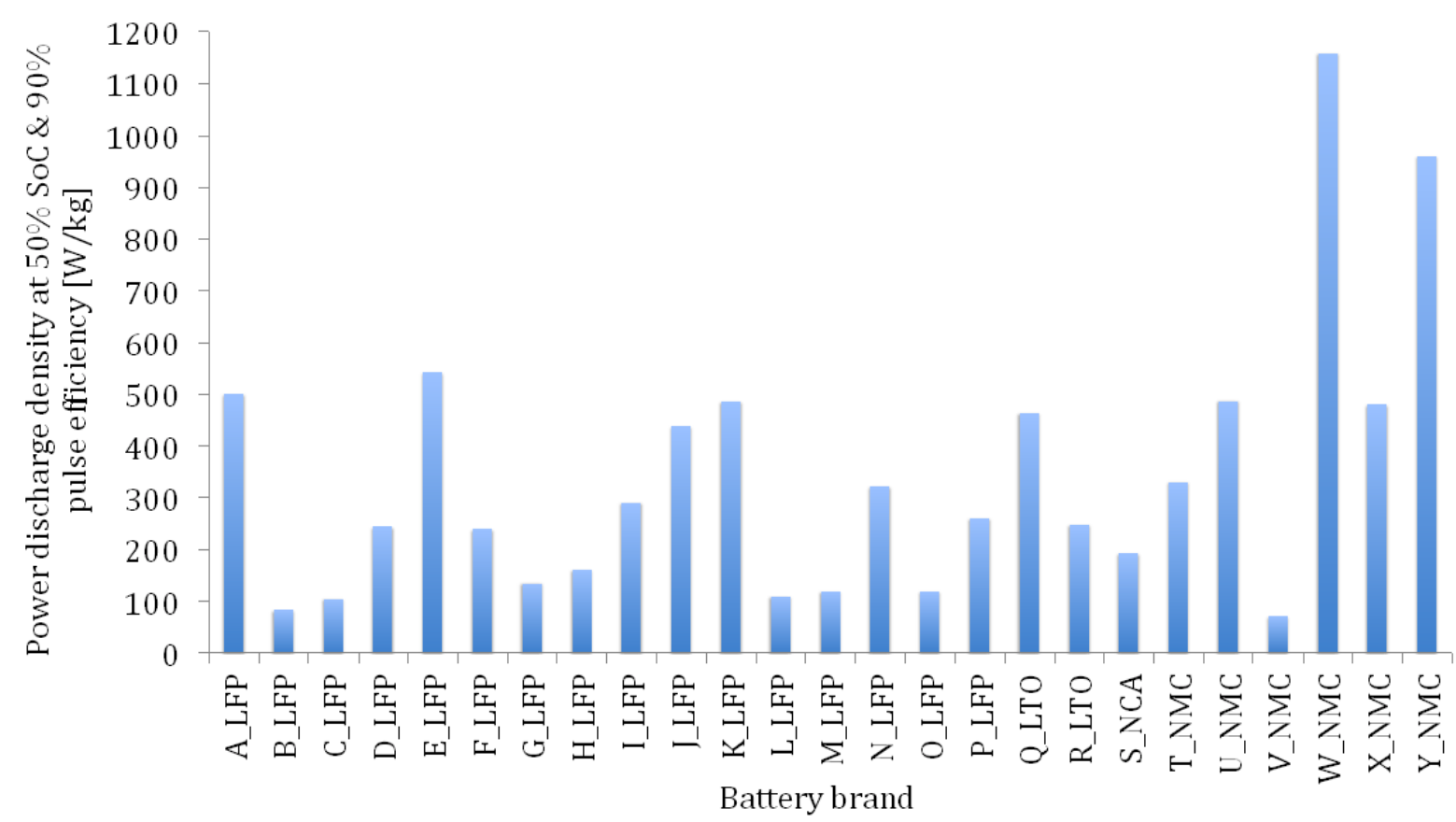

In $[84,85]$ it is mentioned that the energy efficiency of electrochemical processes decreases with increasing current rate, due to the increase of the internal resistance. However, Figure 28 shows the opposite of this explanation. The internal resistance decreases the more the current rate increases.

This phenomenon can be analyzed based on the Butler-Volmer relationship [86], presented in general form by Equation (16):

$$
I=A \cdot I_{0}\left[e^{\left(\frac{\alpha_{a} \cdot n \cdot F}{R \cdot T} \cdot\left(U-U_{0}\right)\right.}-e^{\left(-\frac{\alpha_{c} \cdot n \cdot F}{R \cdot T} \cdot\left(U-U_{0}\right)\right)}\right]
$$

with:

- I: electrode current $[\mathrm{A}]$;

- A: electrode active surface area $\left[\mathrm{m}^{2}\right]$;

- $\mathrm{I}_{\mathrm{o}}$ : exchange current density $\left[\mathrm{A} / \mathrm{m}^{2}\right]$; 
- U: electrode potential [V];

- $\mathrm{U}_{\mathrm{o}}$ : equilibrium potential [V];

- F: Farady constant;

- T: Temperature [K];

- R: Universal gas constant;

- $\alpha_{a}, \alpha_{c}$ : anodic and cathodic charge transfer coefficient, respectively;

- $\mathrm{n}$ : activation overpotential.

The first term in the second part represents the rate of the anodic process and the second term corresponds to the rate of the cathodic process. It should be pointed out that the Butler-Volmer equation does not consider the mass transfer phenomena in the system.

Figure 28. Resistance evolution in function of current rate [61].

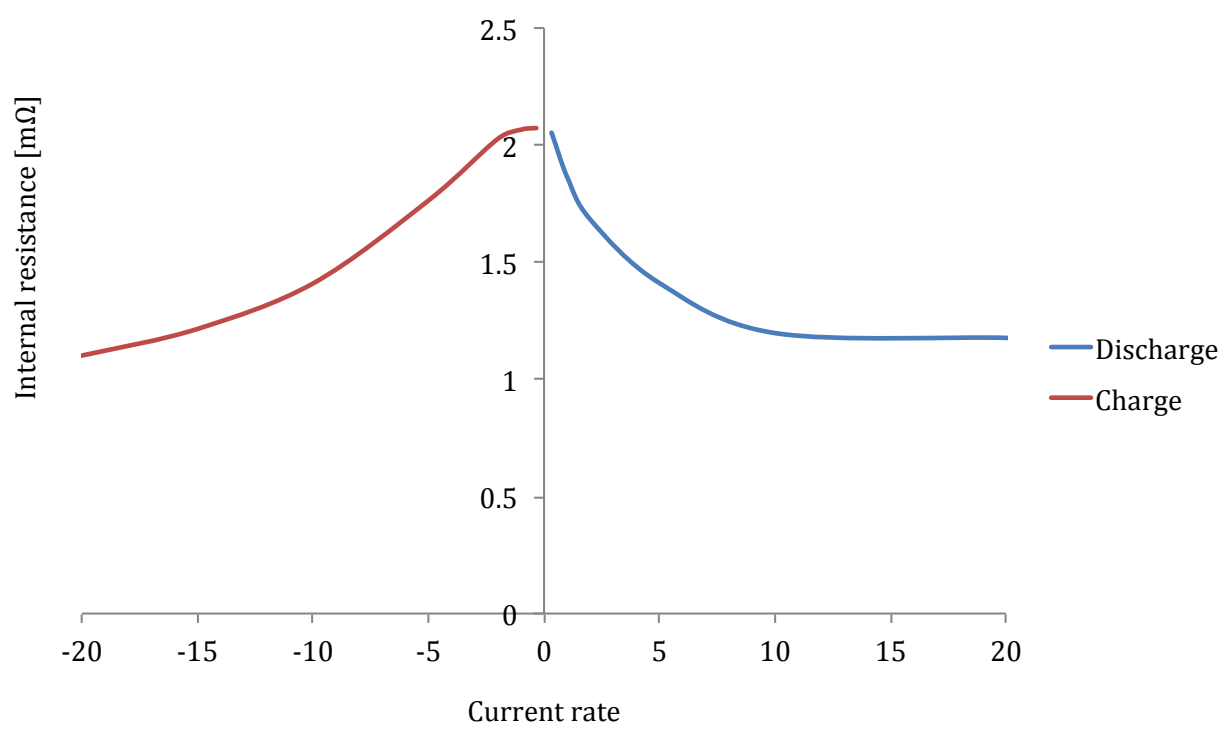

The Butler-Volmer characteristic shows a logarithmical increase of the voltage with increasing current rate rather than a linear relationship Figure 29. Hence the resistance of this process is decreasing. Nevertheless, the overall voltage drop is still increasing with increasing current rate. Therefore the efficiency will decrease with increasing current rate due to the losses in the resistance $\mathrm{R} \cdot \mathrm{I}^{2}$ (see Figure 30 ). Although, the resistance decreases, the impact of current is quadratic.

Figure 29. Butler-Volmer representation [87].

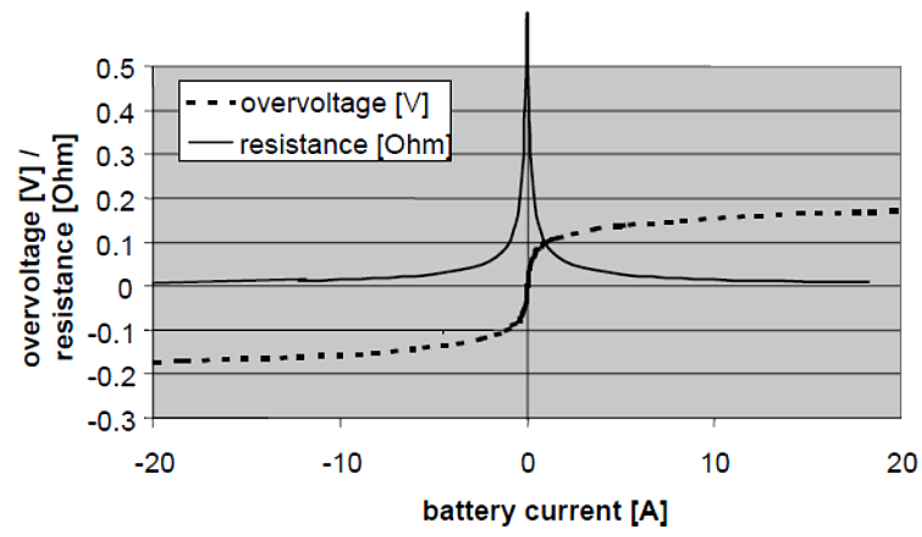


Figure 30. Energy efficiency versus current rate.

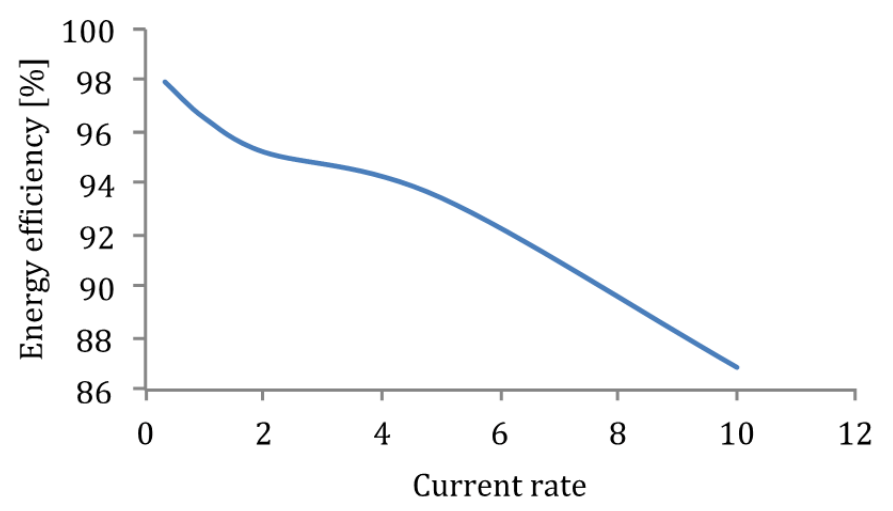

These phenomena only pertain to the voltage response during the polarization part. Thus, the ohmic part which is based on a suddenly voltage drop, is not included. Therefore, there is a need for modification of the Butler-Volmer equation as follows:

$$
I=\frac{U-U_{0}}{I}+A \cdot I_{0}\left[e^{\left(\frac{\alpha . F}{R \cdot T} \cdot\left(U-U_{0}\right)\right.}-e^{\left(\frac{(1-\alpha) \cdot F}{R \cdot T} \cdot\left(U-U_{0}\right)\right.}\right]
$$

The results in Table 8 of EDLCs reveal the high power capabilities of these devices, with power densities up to $11 \mathrm{~kW}$. This indicates again that these performances are very interesting energy sources for high power applications, where peak power should be supplied during short durations. Here, the power density has been determined based on the calculation as described in the standard IEC 62576, $\mathrm{U}$ an $\mathrm{R}$ representing the rated voltage and internal resistance of the ELDC cell as illustrated in Figure 31 [88]:

$$
\mathrm{P}_{\mathrm{EDLC}}=\frac{\mathrm{U}^{2}}{4 \cdot \mathrm{R} \cdot \mathrm{m}}
$$

In [85] Burke proposes the introduction of similar energy efficiency calculations for EDLCs. Due to the lower internal resistance, he specified an energy efficiency of $95 \%$. He came to the conclusion that the proposed methodology by IEC does not match the internal resistance, and proposed the empirical Equation (19). According to this method, the power density is in the range of 1000-1200 W/kg, which is much higher than the capabilities of lithium-ion technology. Here, it should be figured out that high energy lithium-ion batteries can be combined with EDLCs in order to enhance the overall battery abilities in the terms of energy, power and efficiency:

$$
\mathrm{P}_{\mathrm{EDLC}}=\frac{9}{16} \cdot\left(1-\mathrm{E}_{\mathrm{ff}}\right) \cdot \frac{\mathrm{U}^{2}}{\mathrm{R}}
$$


Figure 31. Internal resistance determination method for EDLCs according standard IEC 62576 [88].

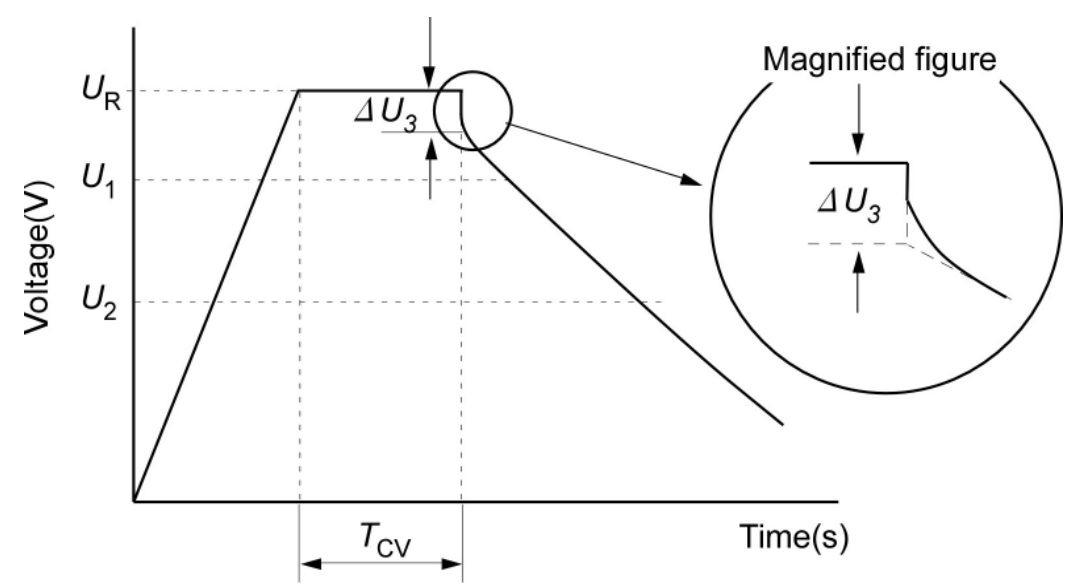

Table 8. Power density results of EDLCs.

\begin{tabular}{lcc}
\hline & $\begin{array}{c}\text { Power density according } \\
\text { IEC methodology }\end{array}$ & $\begin{array}{c}\text { Power density according to [85] } \\
\text { @ 95\% energy efficiency }\end{array}$ \\
\hline A-EDLC & 9773 & 1126 \\
B-EDLC & 11054 & 1261 \\
C-EDLC & 8516 & 958 \\
D-EDLC & 4050 & 998 \\
E-EDLC & 9210 & 1000 \\
F-EDLC & 10279 & 1217 \\
G-EDLC & 8877 & 998 \\
\hline
\end{tabular}

\subsubsection{Lithium-Ion Battery Behaviour Description}

As reported in $[89,90]$ the FreedomCar and Thevenin battery models are derived from the HPPC test. The model has been built based on several assumptions. The ohmic resistance $\mathrm{R}_{\mathrm{o}}$ supposes that the charge and discharge resistance of a battery are equal, as shown in Figure 32 however these two resistances are different. Thus, in order to take this issue into account, the ohmic resistance $\mathrm{R}_{\mathrm{o}}$ should be divided in two parts: charge resistance $\mathrm{R}_{\mathrm{ch}}$ and discharge resistance $\mathrm{R}_{\text {dis }}$. Furthermore, the HPPC pulse assumes a rest time of $40 \mathrm{~s}$ between the charge and discharge pulses is not enough for stabilization of the voltage between two consecutive pulses. This aspect is of high importance for modeling purposes, where the battery model parameters should be extracted at high accuracy. Especially, at higher current rates and low temperatures, the voltage disturbance is bigger. Thus, the rest time between the consecutive pulses should be in the range of 150-200 s. 
Figure 32. Evolution of internal resistance during charge and discharge (battery brand A-LFP).

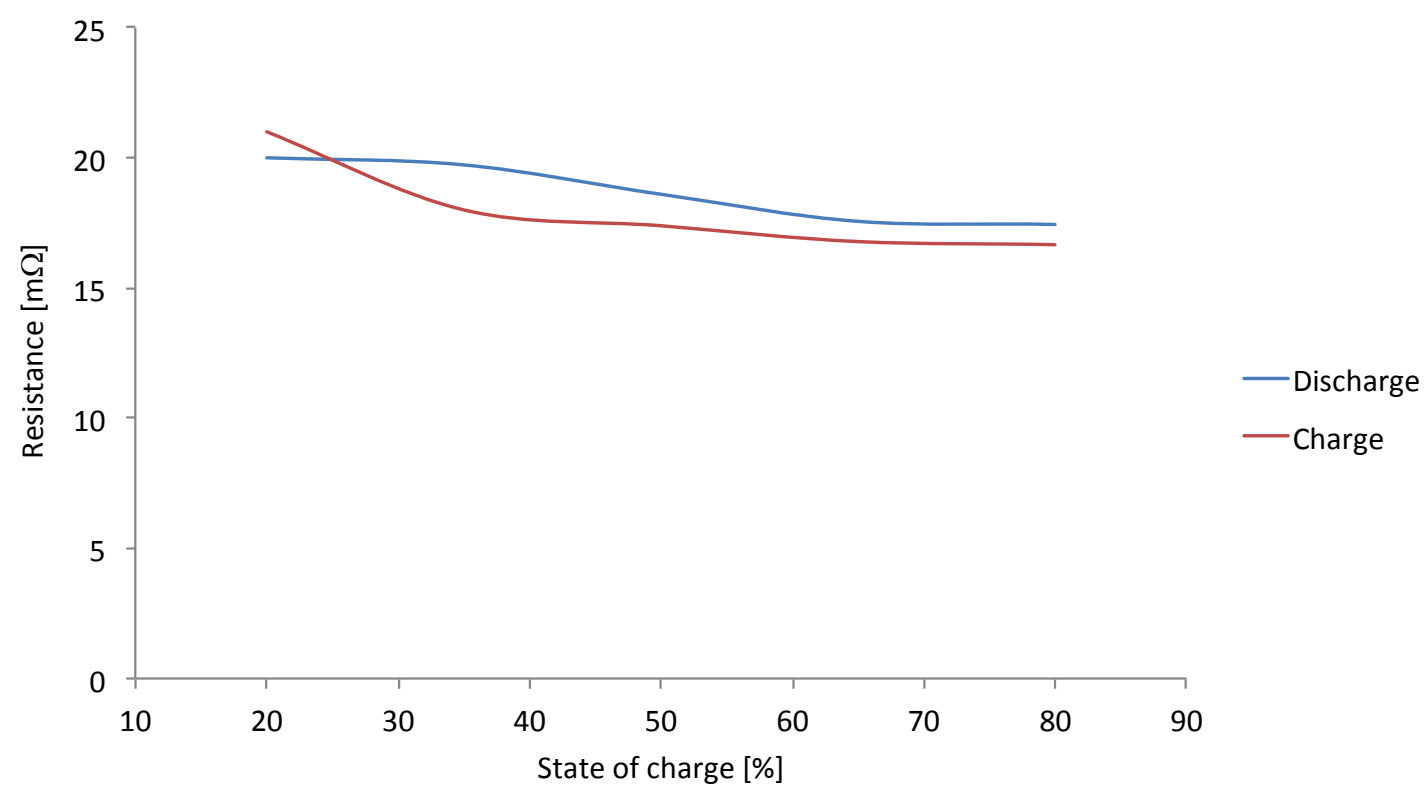

Here, it should be underlined that ohmic resistance represents the sudden voltage drop (from $V_{1}$ to $V_{2}$ in Figure 26), while the voltage drop from $V_{2}$ to $V_{3}$ is the polarization resistance. Moreover, at the end of the pulse, when the load goes to zero, the ohmic resistance seems not equal to the ohmic resistance when the load disappears. As an example the ohmic resistance for both situations has been calculated.

$$
\begin{gathered}
\mathrm{R}_{\text {load }}=\frac{\mathrm{V}_{1}-\mathrm{V}_{2}}{\mathrm{I}}=\frac{3.297-3.165}{11.5}=11.4 \mathrm{~m} \Omega \\
\mathrm{R}_{\text {recovery }}=\frac{\mathrm{V}_{4}-\mathrm{V}_{3}}{\mathrm{I}}=\frac{3.204-3.055}{11.5}=12.9 \mathrm{~m} \Omega
\end{gathered}
$$

It is clear that these two resistances differ from each other and this impact should also be included in the battery model. Then, Figure 26 shows the polarization resistance during the recovery process. As mentioned above, this process needs about $200 \mathrm{~s}$ until the voltage has been stabilized. Finally, all the mentioned processes depend of the charge and discharge processes and thus should be proposed for charge and discharge.

In order to represents all these issue in an electrical circuit, the following model as presented in Figure 33 is proposed. We call this the advanced Thevenin battery model. It consists of two ohmic resistances $R_{o, c h}, R_{o, d i s}$ and two resistances $R_{L, c h}, R_{L, d i s}$ representing the increase of the ohmic resistance in function of cycle life. Furthermore, the model features a self-discharge resistance across the open circuit voltage (VoC). In order to describe the transition phenomena during charge and discharge two $\mathrm{RC}$ circuits have been added. Two further RC branches are also added to represent the polarization phenomena when the load disappears. As discussed above, the resistances $R_{o, \text { rec, ch, }} R_{o, \text { rec,dis }}$ representing the resistances when the load disappears, are also included.

In the next contribution, the performances of this model intensively will be analyzed and compared against another battery models. 
Figure 33. New lithium-ion battery model.

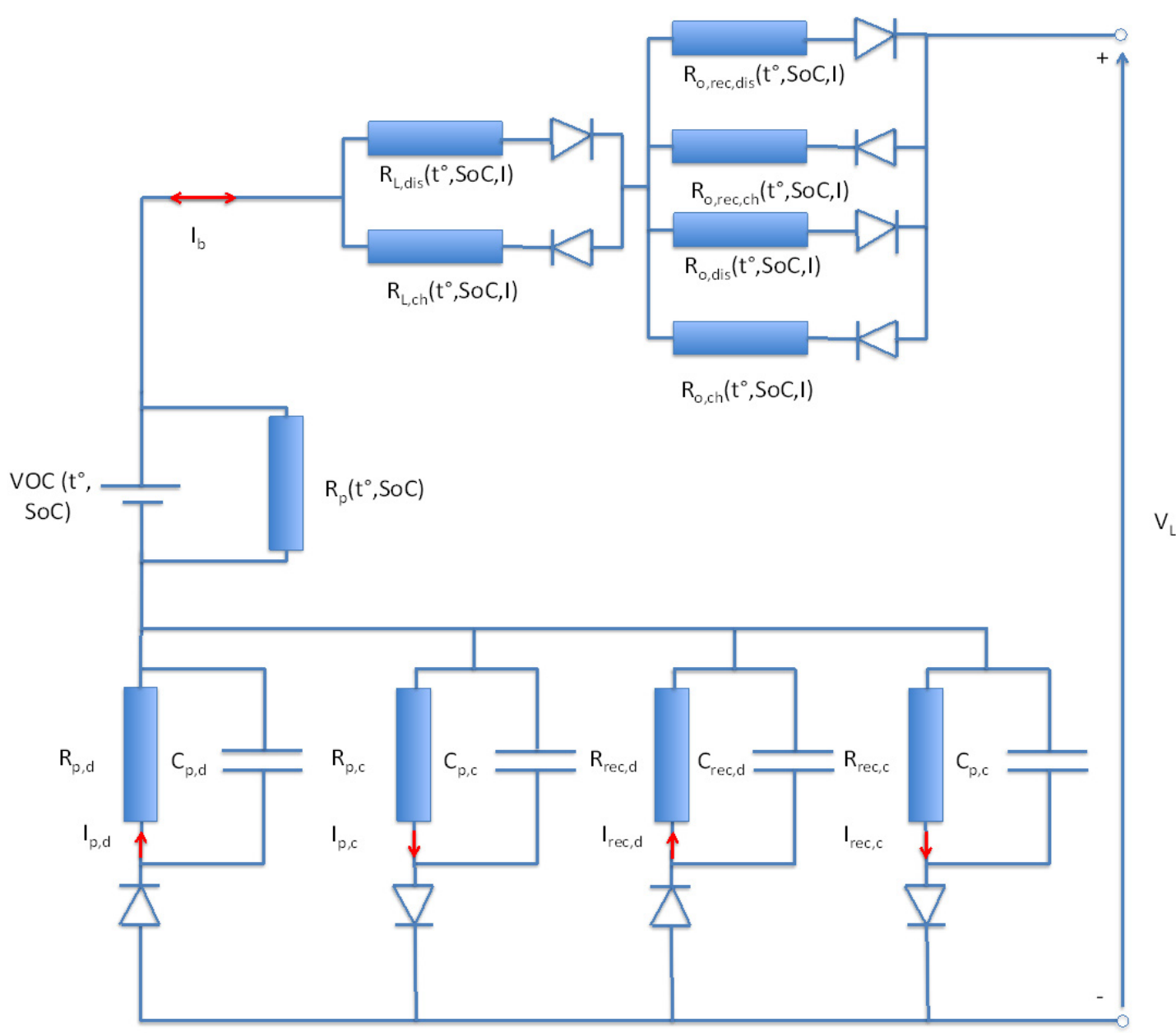

\subsubsection{Self-Discharge Test}

In [61] is reported that the self-discharge test is one of the key consideration parameters in the selection of the appropriate RESS for PHEVs. This parameter is also critical for battery modeling issues. During long periods of non-activity, the SoC loss of the battery will decline and the battery system can fall under the allowed minimal voltage, accelerating battery degradation and causing irreversible capacity loss.

This test has been executed according to the standards ISO 12405-1/2 [79,80]. After a standard cycle at $1 \mathrm{I}_{\mathrm{t}}$ for determining the real cell energy in $\mathrm{Wh}$; the battery cell is left at room temperature $\left(20-24^{\circ} \mathrm{C}\right)$ for 7 days, following by a discharge test:

$$
\text { Energy loss }=\frac{E_{\text {bef }}}{E_{\text {aft }}} .100 \%
$$

As we observe in Figure 34, the energy loss changes between 1\% and 5\% with exception of battery brand $\mathrm{B}$, where the loss is about $9 \%$, while the loss percentage for lead-acid, nickel-metal hydride and EDLC is till 3.5\%, 10\% and 23\%, respectively. The high loss for EDLC again indicates that EDLCs can not be used a main energy storage system. 
Figure 34. State of charge loss of various battery technologies.

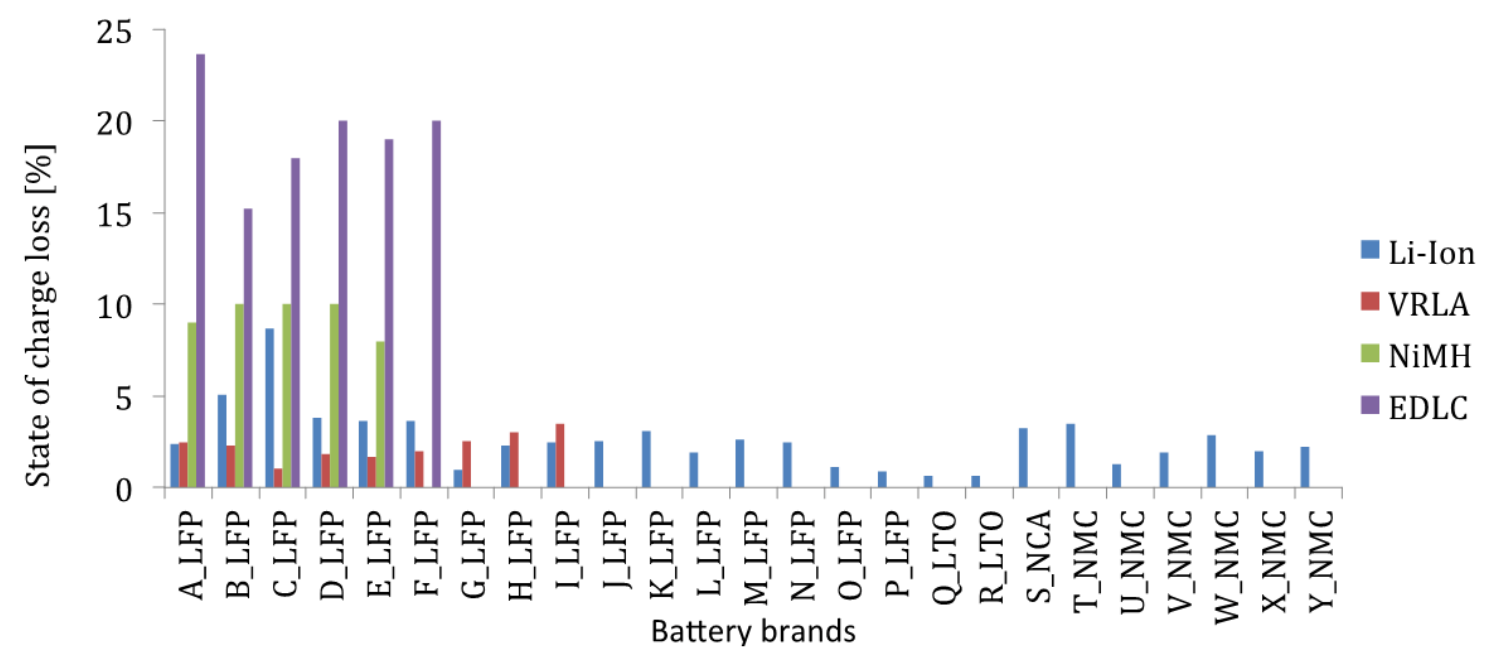

\section{Summary and Conclusions}

In this paper, the performances of various lithium-ion chemistries for use in PHEVs have been investigated and compared to several other RESS technologies such as lead-acid, nickel-metal hydride and EDLCs.

The analysis has shown the beneficial properties of lithium-ion in the terms of energy density, power density and rate capabilities. Particularly, the nickel manganese cobalt oxide cathode stands out with the high energy density up to $160 \mathrm{Wh} / \mathrm{kg}$, compared to $70-110,90$ and $71 \mathrm{Wh} / \mathrm{kg}$ for lithium iron phosphate cathode lithium nickel cobalt aluminum cathode and, lithium titanate oxide anode battery cells, respectively. These values are considerably higher than the VRLA (23-28 Wh/ $\mathrm{kg}$ ) and nickel-metal hydride (44-53 Wh/kg) battery technologies

The dynamic discharge performance test shows that the energy efficiency of the lithium-ion batteries is significantly higher that the VRLA and nickel-metal hydride technologies. The efficiency varies between $86 \%$ and $98 \%$, with the best values obtained by pouch battery cells, before cylindrical and prismatic battery design concepts.

Also from the point of view of the power capabilities, lithium-ion technology is superior compared to the other technologies. The power density is in the range of 300-2400 W/kg against $200-400 \mathrm{~W} / \mathrm{kg}$ and $90-120 \mathrm{~W} / \mathrm{kg}$ for VRLA and NiMH, respectively. However, considering the influence of energy efficiency, the power density is in the range of 100-1150 W/kg. Lithium-ion batteries optimized for high energy are at the lower end of this range and are challenged to meet the USABC, SuperLIB and MIT goals. Their association with EDLCs, which have low energy density (4-6 Wh/ $\mathrm{kg}$ ) but outstanding power capabilities, could prove very interesting.

The study of the rate capabilities for the lithium-ion batteries has allowed a new approach for state of charge estimation has been modified, encompassing all essential performance parameters.

The rate capabilities tests are reflected by Peukert constants, which are significantly lower for lithium-ion batteries than for NiMH and VRLA.

Furthermore, rate capabilities during charging have been investigated. Lithium-ion batteries are able to be stored about $80 \%$ of the capacity at current rate $2 \mathrm{I}_{\mathrm{t}}$, with high power cells accepting over $90 \%$. At higher charging rates of $5 \mathrm{I}_{\mathrm{t}}$ or more, the internal resistance impedes charge acceptance by high energy 
cells. The lithium titanate anode, due to its high surface area $\left(100 \mathrm{~m}^{2} / \mathrm{g}\right.$ compared to $3 \mathrm{~m}^{2} / \mathrm{g}$ for the graphite based anode) performs much better in this respect.

According to these analyses, the lithium-ion behaviour at different conditions has been examined, leading to a new lithium-ion battery model to be compared with existing battery models in future research contributions.

\section{References}

1. IEA (International Energy Agency). Energy Technology Perspectives-Scenarios and Strategies to 2050; OECD Publishing: Paris, France, 2010.

2. Van Mierlo, J.; Maggetto, G. Comparison of the Environmental Damage Caused by Vehicles with Different Alternative Fuel and Drive Trains in a Brussels Context. J. Automob. Eng. 2003, 217, 583-593.

3. Boureima, F.S. Environmental Assessment of Conventional and Alternative Vehicles and Fuels in a Belgian Context. Ph.D. Thesis, Vrije Universiteit Brussel, Brussels, Belgium, September 2011.

4. Axsen, J.; Kurani, K.S.; Burke, A. Are Batteries Ready for Plug-in Hybrid Buyers? J. Transp. Policy 2008, 7, 173-182.

5. Van den Bossche, P.; Vergels, F.; Van Mierlo, J.; Matheys, J.; Van Autenboer, W. Subat: an Assessment of Sustainable Battery Technology. J. Power Sources 2006, 162, 913-919.

6. Axsen, J.; Burke, A.; Kurani, K. Batteries for Plug-in Hybrid Electric Vehicles (PHEVs): Goals and State of the Technology CIRA 2008; Research Report; Institute of Transportation Studies, University of California Davis, Davis, CA, USA, 2008.

7. The Boston Consulting Group. Batteries for Electric Cars: Challenges, Opportunities, and the Outlook to 2020; The Boston Consulting Group: Boston, MA, USA, 31 May 2011.

8. Cooper, A.; Moseley, P. Advanced Lead-Acid Batteries - the Way forward for Low-Cost Micro and Mild Hybrid Vehicles. In Proceedings of the 24th World Battery, Hybrid and Fuel Cell Electric Vehicle Symposium, Stavanger, Norway, May 2009.

9. Lindenmaier, J.; Stiegeler, M.; Kabza, H. Charge/Discharge Load Reduction of Lead Acid Batteries in Micro-Hybrid Vehicles Using Ultra-Capacitor Assistance. In Proceedings of the 24th World Battery, Hybrid and Fuel Cell Electric Vehicle Symposium, Stavanger, Norway, May 2009.

10. Chen, H.; Cong, Th.N.; Yang, W.; Tan, Wh.; Li Y.; Ding, Y. Progress in Electrical Energy Storage System: A Critical Review. J. Prog. Nat. Sci. 2009, 9, 291-312.

11. Omar, N.; Verbrugge, B.; Van den Bossche, P.; Van Mierlo, J. Power and Life Enhancement of Battery-Electrical Double Layer Capacitor for Hybrid Electric and Charge-Depleting Plug-in Vehicle Applications. J. Electrochimica Acta 2010, 55, 7524-7531.

12. Omar, N.; Van Mulders, F.; Van Mierlo, J.; Van den Bossche, P. Assessment of Behaviour of Super Capacitor-battery System in Heavy Hybrid Lift Truck Vehicles. J. Asian Electr. Veh. 2009, 7, 1277-1282.

13. Omar, N.; Al Sakka, M.; Daowd, M.; Coosemans, Th.; Van Mierlo, J.; Van den Bossche, P. Assessment of hebavior of Active EDLC-Battery system in Heavy Hybrid Charge Depleting Vehicles. In Proceedings of the 4th European Symposium on Super Capacitors \& Applications, Bordeaux, France, 21-22 October 2010. 
14. Emadi, A.; Rajashekara, K.; Williamson, S.S.; Lukic, S.M. Topological Overview of Hybrid Electric and Fuel Cell Vehicular Power System Architectures and Configurations. IEEE Trans. Veh. Technol. 2005, 54, 763-770.

15. Van Mierlo, J.; Timmermans, J.M.; Maggetto, G.; Van den Bossche, P. Peak Power Based Fuel Cell Hybrid Propulsion System. World Electr. Veh. Assoc. J. 2007, 1, 54-61.

16. Kötz, R.; Carlen, M. Principles and Applications of Electrochemical Capacitors. J. Intern. Soc. Electrochem. 2000, 45, 2483-2498.

17. Cheng, Y.; Van Mierlo, J.; Van den Bossche, P.; Lataire, Ph. Super Capacitor Based Energy Storage as Peak Power Unit in the Applications of Hybrid Electric Vehicles. In Proceedings of the 3rd IET International Conference on Power Electronics, Machines and Drives; Dublin, Ireland, 2006.

18. Abderrahmane, H.; Emmanuel, B. Assessment of Real Behavior of VHE Energy Storage System in Heavy Vehicles. In Proceedings of EET-2008 European Ele-Drive Conference, Geneva, Switzerland, 2008.

19. Lu, Sh.; Corzine, K.A.; Ferdowsi, M. A New Battery/Ultracapacitor Energy Storage System Design and Its Motor Drive Integration for Hybrid Electric Vehicles. IEEE Trans. Veh. Technol. 2007, 56, 1516-1523.

20. Kromer, M.A.; Heywood, J.B. Electric Powertrains: Opportunities and Challenges in the U.S. Light-Duty Vehicle Fleet, Technical Report from the Sloan Automotive Laboratory; Massachusetts Institute of Technology: Cambridge, MA, USA, 2007.

21. Burke, B.; Miller, M. Performance Characteristics of Lithium-ion Batteries of Various Chemistries for Plug-in Hybrid Vehicles. In Proceedings of the 24th World Battery, Hybrid and Fuel Cell Electric Vehicle Symposium, Stavanger, Norway, May 2009.

22. Omar, N.; Daowd, M.; Verbrugge, B.; Mulder, G.; Van den Bossche, P.; Van Mierlo, J.; Dhaens, M.; Pauwels, S.; Leemans, F. Assessment of Performance Characteristics of Lithium-Ion Batteries for PHEV Vehicles Applications Based on a Newly Test Methodology. In Proceedings the 25th World Battery, Hybrid and Fuel Cell Electric Vehicle Symposium, Shenzhen, China, November 2010.

23. Omar, N.; Verbrugge, B.; Mulder, G.; Van den Bossche, P.; Van Mierlo, J.; Daowd, M.; Dhaens, M.; Pauwels, S. Evaluation of Performance Characteristics of Various Lithium-Ion Batteries for Use in BEV Application. In Proceedings of the IEEE Vehicle Power and Propulsion Conference, Lille, France, September 2010.

24. Omar, N.; Daowd, M.; Mulder, G.; Timmermans, J.M.; Van den Bossche, P.; Van Mierlo, P.; Pauwels, S. Assessment of Performance of Lithium Iron Phophate Oxide, Nickel Manganese Cobalt Oxide and nickel cobalt aluminum oxide Based cells for Using in Plug-In Battery Electric. In Proceedings of the IEEE Vehicle Power and Propulsion Conference, Chicago, IL, USA, September 2011.

25. Peseran, A. Battery Choices and Potential Requirements for Plug-In Hybrids, In Proceedings Plug-In Hybrid Electric Truck Workshop, Los Angeles, CA, USA, February 2007.

26. International Energy Agency. Technology Roadmap-Electric and Plug-in Hybrid Electric Vehicles; OECD Publishing: Paris, France, 2011. 
27. Mauracher, P.; Geuer, W.; Comparison and Evaluation of Nickel-Cadmium, Zinc-Bromine, Sodium-Sulphur, Sodium-Nickelchloride and Lead-Acid Batteries, AVERE Contract P-044 of the EDS Study, Advanced Electric Drive Systems for Buses, Vans and Passenger Cars to Reduce Pollution (EDS); The European Association for Battery, Hybrid and Fuel Cell Electric Vehicles (AVERE): Brussels, Belgium, December 1992.

28. Bauer, H. Automotive Handbook, 4th ed.; Bentley Pub: Warrendaele, PA, USA, 1996.

29. Kida, H.; Kinoshita, A.; Yanagida, K.; Funahashi, A.; Nohma, T.; Yonezu, I. A Study on the Cycle Performance of Lithium Secondary Batteries Using Lithium Nickel-Cobalt Composite Oxide and Graphite/Coke Hybrid Carbon. J. Electrochimica Acta 2002, 47, 1691-1696.

30. Nelson, P.; Amine, Kh. Advanced Lithium-Ion Batteries for Plug-in Hybrid-Electric Vehicles. In Proceedings the 23th World Battery, Hybrid and Fuel Cell Electric Vehicle Symposium, Anaheim, CA, USA, December 2007.

31. Fellner, J.P.; Loeber, G.J.; Sandhu, S.S. Testing of Lithium-Ion 18650 Cells and Characterizing/Predicting Cell Performance. J. Power Sources 1999, 81-82, 867-871.

32. Pesaran, A. Battery Requirement for Plug-In Hybrid Electric Vehicles-Analysis and Rationale. In Proceedings the 23th World Battery, Hybrid and Fuel Cell Electric Vehicle Symposium, Anaheim, CA, USA, December 2007.

33. Burke, A.; Jungers, B.; Yang, Ch.; Ogden, J. Battery Electric Vehicles: An Assessment of the Technology and Factors Influencing Market Readiness, Advanced Energy Pathways (AEP) Project, Task 4.1 Technology Assessments of Vehicle Fuels and Technologies Public Interest Energy Research (PIER) Program California Energy Commission; UC Davis, Institute of Transportation Studies: Davis, CA, USA, June 2007.

34. Rand, D.A.J.; Woods, R.; Dell, R.M. Batteries for Electric Vehicles; Research Studies Press: Taunton, UK; John Wiley \& Sons: New York, NY, USA, 1998.

35. Mancini, M. Improved Anodic Materials for Lithium-ion Batteries: Surface Modification by Metal Deposition and Electrochemical Characterization of Oxidized Graphite and Titanium Dioxide Electrodes. Ph.D. Thesis, University of Camerino, Camerino, Italy, 2008.

36. The Boston Consulting Group. Batteries for Electric Cars: Challenges, Opportunities, and the Outlook to 2020. Available online: http://www.bcg.com (accessed on 31 May 2011).

37. Meeuws, M. Batteries in the cars of the future. Presentation at the summer school, Vrije Universiteit Brussel, Brussel, Belgium, July 2010.

38. Ohzuk, T.; Brodd, R.J. An Overview of Positive-Electrode Materials for Advanced Lithium-Ion Batteries. J. Power Sources 2007, 174, 449-456.

39. Belharouak, I.; Lu, W.; Vissers, D.; Amine, Kh. Safety, Characteristics of $\mathrm{Li}\left(\mathrm{Ni}_{0.8} \mathrm{Co}_{0.15} \mathrm{Al}_{0.05}\right) \mathrm{O}_{2}$ and $\mathrm{Li}\left(\mathrm{Ni}_{1 / 3} \mathrm{Co}_{1 / 3} \mathrm{Mn}_{1 / 3}\right) \mathrm{O}_{2}$. J. Power Sources 2006, 8, 329-335.

40. Belov, D.; Yang, M.H. Investigation of the Kinetic Mechanism in Overcharge Process for Li-ion Battery. Solid State Ion. 2008, 179, 1816-1821.

41. Belov, D.; Yang, M.H. Failure Mechanism of Li-ion Battery at Overcharge Condition. J. Solid State Electrochem. 2008, 12, 885-894.

42. DoH, C.H.; Kim, D.H.; Kim, H.S.; Shin, H.M.; Jeong, Y.D.; Moon, S.I.; Jin, B.S.; Eom, S.W.; Kim, H.S.; Kim, K.W.; Oh, D.H.; Veluchamy, A. Thermal and Electrochemical Behaviour of $\mathrm{C} / \mathrm{Li}_{\mathrm{x}} \mathrm{CoO}_{2}$ Cell During Safety Test. J. Power Sources 2008, 175, 881-885. 
43. Takahashi, Y.; Tode, S.; Kinoshita, A.; Fujimoto, H.; Nakane, I.; Fujitani, S. Development of Lithium-Ion Batteries with a $\mathrm{LiCoO}_{2}$ Cathode Toward High Capacity by Elevating Charging Potential. J. Electrochem. Soc. 2008, 155, A537-A541.

44. Amatucci, G.G.; Tarascon, J.M.; Klein, L.C. Cobalt Dissolution in $\mathrm{LiCoO}_{2}$ Based Non-Aqueous Rechargeable Batteries. J. Solid State Ion. 1996, 83, 169-173.

45. Amatucci, G.G.; Tarascon, J.M.; Klein, L.C. $\mathrm{CoO}_{2}$, the End Member of the $\mathrm{Li}_{\mathrm{x}} \mathrm{CoO}_{2}$ Solid Solution. J. Electrochem. Soc. 1996, 143, 1114-1123.

46. Ferguson, J.W. Recent Developments in Cathode Materials for Lithium-Ion Batteries. J. Power Sources 2010, 195, 939-954.

47. Kang, K.; Meng, Y.S.; Breger, J.; Grey, C.P.; Ceder, G. Electrodes with High Power and High Capacity for Rechargeable Li Batteries. J. Sci. 2006,311, 977-980.

48. Amriou, T.; Khelifa, B.; Aoutag, K.; Aouadi, S.M.; Mathieu, C. Ab Initio Investigation of the Jahn-Teller Distortion Effect on the Stabilizing Lithium Intercalated Compounds. J. Mater. Chem. Phys. 2005, 92, 499-504.

49. Liu, H.; Yang, Y.; Zhang, J. Reaction Mechanism and Kinetics of Lithium Ion Battery Cathode Material $\mathrm{LiNiO}_{2}$ with $\mathrm{CO}_{2}$. J. Power Sources 2007, 173, 556-561.

50. Padhi, A.K.; Nanjundaswamy, K.S.; Goodenough, J.B. Phospho-olivines as Positive-Electrode Materials for Rechargeable Lithium Batteries. J. Electrochem. Soc. 1997, 144, 1188-1194.

51. Ong, Sh.P. First Principle Design and Investigation of Lithium-Ion Battery Cathodes and Electrolytes, Ph.D. Thesis, Massachusetts Institute of Technology, Cambridge, MA, USA, February 2011.

52. Wakihara, M. Recent Development in Lithium Ion Batteries. J. Mater. Sci. Eng. 2001, R33, 109-134.

53. Winter, M.; Besenhard, J.O.; Spahr, M.E.; Novak, P. Insertion Electrode Materials for Rechargeable lithium Batteries. J. Adv. Mater. 1998, 10, 725-763.

54. Broussely, M.; Archdale, G. Li-ion Batteries and Portable Power Source Prospects for the Next Five to Ten Years. In Proceedings of the 23rd International Power Sources Symposium, Amsterdam, The Netherlands, September 2003.

55. Colbow, K.M.; Dahn, J.R.; Haering, R.R. Structure and electrochemistry of the spinel oxide $\mathrm{LiTiO}_{4}$ and $\mathrm{Li}_{4 / 3} \mathrm{Ti}_{5 / 3} \mathrm{O}_{4}$. J. Power Sources. 1989, 26, 397-402.

56. Wenige, R.; Niemann, M.; Heider, U.; Jungnitz, M.; Hilarius, V. Liquid Electrolyte Systems for Advanced Lithium Batteries. In Proceedings of the Industrial Chemistry Symposium, Seoul, Korea, 1997.

57. Pesaran, A.; Market, T.; Tataria, H.; Howell, D. Battery requirements for plug- in hybrid electric vehicles: analysis and rationale. In Proceedings the 23th World Battery, Hybrid and Fuel Cell Electric Vehicle Symposium. Anaheim, CA, USA, December 2007.

58. Graham, R. Comparing the Benefits and Impacts of Hybrid Electric Vehicle Options; Technical Report; Electric Power Research Institute (EPRI): Palo Alto, CA, USA, 2001.

59. SuperLIB. Available online: http://www.superlib.eu/ (access on 17 November 2011).

60. Mulder, G.; Omar, N.; Pauwels, S.; Leemans, F.; Verbrugge, B.; De Nijs, W.; Van den Bossche, P.; Six, D.; Van Mierlo, J. Enhanced Test Methods to Characterise Automotive Battery Cells. J. Power Sources 2011, 196, 100079-10087. 
61. Omar, N.; Daowd, M.; Hegazy, O.; Mulder, G.; Timmermans, J.M.; Coosemans, Th.; Van Den Bossche, P.; Van Mierlo, J. Standardization Work for BEV and HEV Applications: Critical Appraisal of Recent Traction Battery Documents. Energies 2012, 5, 138-156.

62. European Batteries. Available online: http://www.europeanbatteries.com/solutions/brochures (accessed on 22 November 2011).

63. EIG Batteries. Available online: http://www.eigbattery.com/ (accessed on 22 November 2011).

64. Simon, P.; Burke, A.F. Nanostructured Carbons: Double-Layer Capacitance and More? Electrochem. Soc. Interface 2008, 17, 38-41.

65. Burke, A.F. R\&D Considerations for the Performance and Applications of Electrochemical Capacitors. J. Electrochimica Acta 2007, 53, 1083-1091.

66. Muratori, M. Thermal Characterization of Lithium-Ion Battery Cell, Master's Thesis, Politecnico Di Milano, Milan, Italy, June 2009.

67. Nissan Leaf Wikipedia page. Available online: http://en.wikipedia.org/wiki/Nissan_Leaf (accessed on 24 November 2011).

68. Opel Ampera Slide Share. Available online: http://www.slideshare.net/AltairHTC/electricvehicles-10206050 (accessed on 24 November 2011).

69. Daowd, M.; Omar, N.; Van den Bossche, P.; Van Mierlo, J. Passive and Active Battery Balancing comparison based on Matlab Simulation. In Proceedings of 2011 IEEE Vehicle Power and Propulsion Conference (VPPC 2011), Chicago, IL, USA, September 2011.

70. Ershag, O. A Balancing and Monitoring System for Battery Cell Stacks in Electrical Vehicles, Master's Thesis, Lulea University of Technology, Strömsund, Sweden, June 2008.

71. Tahil, W. How Much Lithium does a Lilon EV battery really need? Available online: http://www.meridian-int-res.com (access on Day Month Year).

72. Peukert, W. Über die Abhänigkeit der Kapazität von der Entladestromstärke bei Bleiakkumulatoren. Elektrotechnische Zeitschrift 1897, 27, 287-288.

73. Szczepanek, A.; Botsford, C. Electric Vehicle Infrastructure Development: An Enabler for Electric Vehicle Adoption. In Proceedings the 24th World Battery, Hybrid and Fuel Cell Electric Vehicle Symposium, Stavanger, Norway, May 2009.

74. Van den Bossche, P.; Omar, N.; Van Mierlo, J. Trends and Development Status of IEC Global Electric Vehicle Standards. J. Asian Electr. Veh. 2010, 8, 1409-1414.

75. Van den Bossche, P.; Verbrugge, B.; Omar, N.; Van Mierlo, J. The Electric Vehicle Charged by the Grid: Voltages and Power Levels. In Proceedings of the Plug in Hybrid and Electric Vehicles Conference (PHEV-09), Montréal, Canada, September 2009.

76. IEC 61851-1: Electric vehicle conductive charging system-Part 1: General requirements, 2010. Available online: http://webstore.iec.ch/webstore/webstore.nsf/Artnum_PK/44636 (accessed on 17 November 2011).

77. Sawai, K.; Yamato, R.; Ohzuku, T. Impedance on Lithium-Ion Battery Consisting of $\mathrm{Li}\left(\mathrm{Li}_{1 / 3} \mathrm{Ti}_{5 / 3}\right) \mathrm{O}_{4}$ and $\mathrm{LiCO}_{1 / 2} \mathrm{Ni}_{1 / 2} \mathrm{O}_{2}$. J. Electrochem. 2005, 51, 1651-1655.

78. IEC 60254-1: Lead-acid traction batteries_-Part 1: General requirement and methods of test, April 2005. Available online: http://webstore.iec.ch/preview/info_iec60254-1\%7Bed4.0\%7Den_d.pdf (accessed on 17 November 2011). 
79. ISO 12405-1 Electrically propelled road vehicles-Test specification for lithium-ion traction battery packs and systems-Part 1: High- power applications, June 2011. Available online: http://www.iso.org/iso/catalogue_detail?csnumber=51414 (accessed on 17 November 2011).

80. ISO 12405-2 Electrically propelled road vehicles-Test specification for lithium-ion traction battery packs and systems-Part 1: High- energy applications, June 2011. Available online: http://www.iso.org/iso/catalogue_detail?csnumber=55854 (accessed on 17 November 2011).

81. IEC 62660-1 Ed. 1: Secondary batteries for the propulsion of electric road vehicles-Part 1: Performance testing for lithium-ion cells, May 2010. Available online: http://webstore.iec.ch/ webstore/webstore.nsf/artnum/044728!opendocument (accessed on 17 November 2011).

82. Nazri, G.B.; Pistoia, G. Lithium Batteries; Springer: New York, NY, USA, 2009.

83. Patterson, M.L. Anode Materials for Lithium Ion Batteries. In Proceedings Indiana University Battery Workshop, Indiana, IN, USA, November 2009.

84. Sarre, G.; Blanchard, Ph.; Broussely, M. Aging of Lithium-Ion Batteries, J. Power Sources 2004, $127,65-71$.

85. Burke, A. Ultracapacitor Technologies and Application in Hybrid and Electric Vehicles. Interna. J. Energy Res. 2010, 34, 133-151.

86. Kharkats, Y.I.; Sokirko, A.V.; Bark, F.H. Properties of Polarization Curves for Electrochemical Cells Described by Butler-Volmer Kinetics and Arbitrary Values of the Transfer Coefficient. $J$. Electrochimica Acta 1995, 40, 247-252.

87. Uwe Sauer, D. Cursus Electrochemistry; University of Aachen: Aachen, Germany, 2009.

88. IEC 62576: Electric Double-Layer double for Use in Hybrid Electric Vehicles-Hybrids Test Methods for Electrical Characteristics, April 2008. Available online: http://webstore.ansi.org/ RecordDetail.aspx?sku=IEC+62576+Ed.+1.0+b:2009 (accessed on 17 November 2011).

89. Verbrugge, B.; Heremans, Y.; Van Mulders, F.; Culcu, H.; Van den Bossche, P.; Van Mierlo, J. Modelling the RESS: Describing Electrical Parameters of Batteries and Electric Double-Layer Capacitors through Measurements. World Electr. Veh. J. 2009, 3, 1-9.

90. Daowd, M.; Omar, N.; Van den Bossche, P.; Van Mierlo, J. An Extended PNGV Battery Model for Electric and Hybrid Vehicles. Int. Rev. Electr. Eng. 2011, 6, 1692-1706.

(C) 2012 by the authors; licensee MDPI, Basel, Switzerland. This article is an open access article distributed under the terms and conditions of the Creative Commons Attribution license (http://creativecommons.org/licenses/by/3.0/). 